AperTO - Archivio Istituzionale Open Access dell'Università di Torino

\title{
Clinical insights gained through metabolomic analysis of human breast milk
}

\section{This is the author's manuscript}

Original Citation:

Availability:

This version is available http://hdl.handle.net/2318/1733920

since 2020-10-19T16:04:42Z

Published version:

DOI:10.1080/14789450.2019.1703679

Terms of use:

Open Access

Anyone can freely access the full text of works made available as "Open Access". Works made available under a Creative Commons license can be used according to the terms and conditions of said license. Use of all other works requires consent of the right holder (author or publisher) if not exempted from copyright protection by the applicable law. 


\section{Expert Review of Proteomics}

ISSN: 1478-9450 (Print) 1744-8387 (Online) Journal homepage: https://www.tandfonline.com/loi/ieru20

\section{Clinical insights gained through metabolomic analysis of human breast milk}

\section{Flaminia Bardanzellu, Chiara Peila, Vassilios Fanos \& Alessandra Coscia}

To cite this article: Flaminia Bardanzellu, Chiara Peila, Vassilios Fanos \& Alessandra Coscia (2019): Clinical insights gained through metabolomic analysis of human breast milk, Expert Review of Proteomics, DOI: 10.1080/14789450.2019.1703679

To link to this article: https://doi.org/10.1080/14789450.2019.1703679

Accepted author version posted online: 11 Dec 2019.

Submit your article to this journal $\pi$

Q View related articles $\longleftarrow$

View Crossmark data $₫$ 
Publisher: Taylor \& Francis \& Informa UK Limited, trading as Taylor \& Francis Group

Journal: Expert Review of Proteomics

DOI: $10.1080 / 14789450.2019 .1703679$

\section{Review}

\section{Clinical insights gained through metabolomic analysis of human breast} milk

Flaminia Bardanzellu ${ }^{1}$, Chiara Peila², Vassilios Fanos ${ }^{1}$, Alessandra Coscia $^{2}$

${ }^{1}$ Neonatal Intensive Care Unit, Department of Surgical Sciences, AOU University of Cagliari, Italy. SS 554 km 4,500, 09042 Monserrato CA

${ }^{2}$ Neonatology Unit, Department of Public Health and Pediatrics, Università degli Studi di Torino, Turin, Italy

\section{Correspondence:}

Bardanzellu Flaminia,

Email: bardanzellu.flaminia@virgilio.it

Phone: $+3970 / 51093426$ 


\section{Abstract}

Introduction: Among the OMICS technologies, that have emerged in recent years, metabolomics has allowed relevant step forwards in clinical research. Several improvements in disease diagnosis and clinical management have been permitted, even in neonatology. Among potentially evaluable biofluids, breast milk (BM) results are highly interesting, representing a fluid of conjunction between mothers newborns, describing their interaction.

Areas covered: in this review, updating a previous review article, we discuss research article and reviews on BM metabolomics and found in MEDLINE using metabolomics, breast milk, neonatal nutrition, breastfeeding, human milk composition and preterm neonates as keywords.

Expert opinion: Our research group has a profound interest in metabolomics research. In 2012, we published the first metabolomic analysis on BM samples, reporting interesting data on its composition and relevant differences with formula milk (FM), useful to improve FM composition. As confirmed by successive studies, such technology can detect the specific BM composition and its dependence on several variables, including lactation stage, gestational age, maternal or environmental conditions. Moreover, since BM contaminants or drug levels can be detected, metabolomics also results useful to determine BM safety. These are only few practical applications of BM analysis, which will be reviewed in this paper.

Keywords: Breast milk composition, breast milk contaminants, breastfeeding, formula milk, health outcome, lactation stage, micronutrients, neonatal nutrition, neurodevelopment, premature newborns. 


\section{Article highlights}

- Breastfeeding is beneficial for both newborn and his mother, although BM components and their properties are not fully understood;

- Metabolomics provides a complete and dynamic analysis of BM samples, obtained in a non invasive way;

- Such technology allows a full characterization of BM and determination of its variations over lactation stages;

- Metabolomics allows the comprehension of maternal factors affecting BM composition;

- The characterization of BM metabolome in each category of newborns allows the comprehension of milk variations in more vulnerable patients;

- Metabolomics can describe the effects of BM components on gut microbiome of breastfed infant;

- Metabolomics can compare BM, FM and other kinds of milk, allowing the realization of improved formulas;

- Interesting findings are also reported in animal or in vitro models, suggesting ideas for future research;

- BM contaminants, adulterants, drugs or the levels of micronutrients can be detected;

- Metabolomic analysis can describe the effects of several treatments on milk samples;

- BM metabolomics can be correlated with several neonatal or infantile outcomes;

- The contemporary analysis of more biofluids from the same subject can detect the direct effects of nutrition on neonatal metabolome;

- An integrated approach based on the combination of several techniques could be useful;

- New approaches or more innovative techniques will improve the accuracy of BM analysis. 


\section{INTRODUCTION}

Human breast milk (BM) is the ideal food for newborns and infants, highly bioavailable and easy to digest. This nourishment is unique: it is a specie-specific biological dynamic fluid which can change significantly from one woman to another. Moreover, BM varies constantly during lactation to adapt itself to the physiological needs of the developing infant $[1,2]$. This is also due to the gradual maturation of the mammary gland, which depends on the placenta and thus on the progress of the pregnancy [3]. World Health organization (WHO) recommends breastfeeding as the best nutrition for the growth and development of all infants and as an integral part of the reproductive process $[4,5]$. In addition, maternal BM is the only nutrition "customized" to each neonate; literature data report that $\mathrm{BM}$ meets the nutritional needs of term newborns, without supplementation, for the first 6 months of postnatal life. Breastfeeding continuation is then considered optimal for at least 1 and up to 2 years or longer, with age-appropriate complementary feeding [6-8].

These recommendations are also due to the beneficial effects of BM on short- and long-term maternal and infant health outcomes $[1,4,5,9]$. Specifically, lactation has been shown to have beneficial effects on maternal glucose metabolism [10-12] and BM is still the most critical factor in the protection against infections for both term and preterm newborns [13,14]. Colostrum (i.e., milk expressed for the first 5 days after birth) has not only a nutritional role, but also immunological and trophic functions. It is involved in the immunological maturation of the intestine and contains a great amount of peptides with antihypertensive, antimicrobic and anti-inflammatory properties, having a critical role in preventing necrotizing enterocolitis (NEC) and late-onset sepsis and retinopathy of prematurity in preterm babies. These components, also present in mature milk (MM, defined as milk secreted after the $15^{\text {th }}$ day from birth), support intestinal trophism, induce maturation of the immune system, mitigate inflammation, and avoid dysbiosis. In addition, epidemiologic evidence has shown several long-term protective effect of breastfeeding against metabolic syndromes, obesity and type 2 diabetes in offspring [15-18], while at the same time suggesting a role in improving neurodevelopmental outcome of preterm infants $[19,20]$. This benefits are related to the unique "universe" of biological active components present in BM. It consists of $88 \%$ water and contains $10,000-13,000,000$ cells $/ \mathrm{mL}$. In addition to the classical nutrients (such as proteins, carbohydrates, lipids, vitamins, and minerals), BM contains several variable bioactive molecules such as growth factors (GFs), enzymes, hormones, cytokines, chemokines, oligosaccharides (HMOs) and antimicrobial compounds. Moreover, nonprotein molecules containing nitrogen (creatine, amino acids, nucleotides, polyamines) and nonpolar lipids have been described. All these components are necessary for the optimal development of the newborn. A complete review of the actual knowledge regarding BM metabolites, especially small metabolites ( $<1500 \mathrm{Da}$ ) and their effect on breastfed neonates development can be found in the paper of Garwolińska and colleagues [21]. 
Many factors are recognized to influence BM composition: lactation phase, day moment, GA at birth, age of the newborn, gestational pathologies, mother's nutritional status, geographic provenience and metabolic pathways during pregnancy $[22,23]$.

Thus, BM can modify itself according to neonatal needs during growth and development [24]. Moreover, BM components can influence neonatal gut microbiome, allowing the growth of beneficial bacterial species instead of pathogens [25].

The fact that BM composition can be modified by several factors is also essential to adapt to the nutritional needs of premature newborns, which are unique and multifaceted. The BM of mothers having delivered preterm has a distinct composition: it is initially high in protein, fat, free amino acids, and sodium, but over the first few weeks following delivery these levels decrease. On the other hand, the mineral content (including trace minerals) of preterm milk is similar to that of term milk, with the following exceptions: Calcium is significantly lower in preterm milk (and does not increase over time) whereas Copper and Zinc content are both higher in preterm milk and decrease over the time of lactation [26,27].

To meet the unique nutritional requirements of preterm infants while preserving the benefits of breastfeeding, BM should be fortified to allow adequate growth and bone mineralization.

The fortification of BM with more than one nutritional component is associated with short-term improvements in weight gain, linear and head growth. The optimal method for BM fortification remains to be determined, and a variety of protocols are currently used in neonatal units. For instance, it has been observed that the protein content of BM after standard fortification (which is typically based on the customary assumptions on BM composition) fails to meet the recommended intake for preterm infants in approximately $50 \%$ of cases. Low protein intake has been proven to be the primary limiting factor for growth failure in preterm infants.

However, the protein concentration of preterm BM is variable and decreases with the duration of lactation. Recently, good results have been obtained with individual fortification of human milk that compensates for the high variability of expressed BM composition, particularly for protein and fat content. There are two models of individualization: the "adjustable fortification" based on the infant's metabolic response and the "targeted fortification" based on the analysis of human milk and on its fortification in such a way that each infant always receives the amount of needed nutrients [28].

BM is a complex system, only partially understood and characterized. New and promising techniques, such as metabolomics, could allow us to expand our knowledge in this field. Metabolomics investigates the whole of products of metabolism in biological liquids, like BM, to detect the dynamic interactions among different components of such biological system [29]. Thanks to its capacity to describe hundreds of small molecules and determine the characteristic signatures of the entire metabolism in biological processes, metabolomics is a most useful instrument in responding to a wide variety of biological issues [30]. 
The three principal analytical techniques applied in metabolomics studies are nuclear magnetic resonance (NMR), gas chromatography coupled to mass spectrometry (GC-MS) and liquid chromatography coupled with single-stage mass spectrometry (LC-MS) [31,32].

Due to the specific advantages and disadvantages of each of these platforms, they result highly complementary and the integration of multiple technologies is required for a complete characterization of the metabolites in a sample. In metabolomics, the technique of choice depends on several factors, such as the study design, the kind of samples, the costs and the expertise of the operators.

NMR, highly automatable and reproducible, is the ideal tool for long-term or large-scale clinical metabolomics studies; moreover, it also allows metabolic analysis of living samples and results useful to detect sugars, organic acids, and polar compounds. Despite these advantages, NMR is less sensitive than LC-MS and GC-MS, with limits of detection about 10-100 times higher; however, LC-MS and GC-MS methods can not be used to analyze living samples [31]. Further details and a complete comparison among such three platforms in metabolomics can be found in the very recent review of Emwas and colleagues [31].

The identification of specific alterations in metabolomic profiles can improve our knowledge of pathophysiological processes. At the same time, it may represent a useful instrument in disease diagnosis and therapy monitoring. The application of metabolomics in neonatology offers an innovative and promising approach to investigate the complex relationships occurring between nutrition and infant's health. The characterization of BM metabolome and its comparison to formula milk (FM) allows understanding how each nutrient affects neonatal metabolism, and offers the chance to intervene on the diet composition according to the exact nutritional request of the neonate. The complete study of the entire metabolomic spectrum of milk requires the combination of different techniques since the metabolites described are quite numerous and require an extensive and global study.

In addition to several well-known BM beneficial effects, current research is pointing out new evidence and promising fields of application. I.e., According to a recent study, human BM administration in children aged 0-5 years the from 3 days before to 14 days after bone marrow transplant would reduce intestinal inflammation (observed through metabolomics analysis of stools) and could be a valuable adjunct for patients after bone marrow transplant [33].

In this review, we analyze and discuss literature data concerning the BM metabolome, to improve the current knowledge on the metabolic variability of the BM through the phases of lactation, its variations according to $\mathrm{GA}$ at birth and mother gestational pathologies.

The first application of metabolomics to highlight BM features was performed by our study group and published in the article of Cesare Marincola et al. in 2012 [34]. Subsequently, several authors described metabolic pathways of BM samples collected from different cohort of mothers at different times of lactation [3,35-38]. These studies and the principal findings have been reported for the first 
time in a review article by our group, in 2015 evidencing a high BM variability during the first three months of lactation, a high dependence on gestational age (GA) at birth and different metabolic features comparing colostrum and MM [39]. Moreover, preterm samples seem characterized by higher levels of metabolites promoting energy production and cerebral growth, adapting to premature newborns needs [40].

The aim of this review is summarizing the results of metabolomics studies on BM, updating and integrating the review of Cesare-Marincola 2015 [39] and, as in such paper, resuming main results and sample characteristics in a detailed table (Table 1).

For the literature update, we used research articles and reviews found on MEDLINE using metabolomics, breast milk, neonatal nutrition, breastfeeding, human milk composition and preterm neonates as key words.

Then we discuss main results of such papers, classified in paragraphs according to the kind of the study and the areas of investigation.

\section{EXPERIENCES FROM ANIMAL OR CELLULAR MODELS}

In BM research, some metabolomics interesting data came from in vitro or animal models. Below, we report recent and interesting findings on this topic.

In weanling rats, metabolomics allowed the investigation of BM or FM effects on gut microbiome and plasma metabolome [41], underlining the importance of a combined approach to evaluate the correlations between BM and consequent metabolic pathways in breastfed subjects.

Through the analysis of bovine milk samples, the effects of different dairy procedures on milk metabolites were studied. Lipid fraction of organic vs conventional bovine milk result different, confirming the promising metabolomics role also in the evaluation of different milk treatments [42]. In an experimental model of Streptococcus uberis mastitis in dairy cows, milk evidenced a specific peptidomic variation in relation to the inflammatory status [43].

Metabolomic results can be useful to investigate the effects of each component on health outcome. Milk fat globule membrane (MFGM) supplementation in BM was showed to improve brain development and neurocognitive outcomes in rats [44]; metabolomic variations in pig colostrum, depending on pig breeds and parity, could affect piglets' outcome and survival [45].

A recent study highlighted for the first time the effects of prebiotic bovine milk oligosaccharides (BMO) addition in a high-fat (HF) diet-induced obesity in mice; the addiction of BMO seems contrast weight gain. Moreover, it could completely prevent intestinal permeability and intestinal dysbiosis, increasing the level of beneficial species such as Bifidobacteria spp. and Lactobacilli spp. [46].

The supplementation with sialylated bovine milk oligosaccharides (S-BMO) seem also to improve growth in a murine and in a pig model, whose gut microbiota was modified resembling that of 6 - 
month old undernourished stunted Malawian infants, after a fecal transplant. It was observed that S-BMO can determine lean body mass gain, also improving bone morphology, and liver, muscle and cerebral metabolism [47].

In the same research field, Cowardin and co-workers [48] recently colonized young germ-free mice with the gut microbiota of a stunted 6-mo-old infant, demonstrating a decreased bone reabsorption, osteoclastogenesis, increased femoral trabecular bone and cortical thickness after the supplementation with some purified S-BMO, through a gut microbiota-bone axis interaction [48]. Although preliminary, these findings suggest an interaction occurring between S-BMO and gut microbiota, potentially improving future therapeutic strategies for neonatal development and resulting promising in children undernutrition, that represents a global health problem. The effects of HMOs on neonatal brain development have been recently evaluated in a preterm-pig model by Obelitz-Ryom and colleagues [49]. At 3 weeks of age, after the supplementation with oligosaccharide-enriched whey with sialyllactose, preterm pigs showed improved functional brain performances and spatial cognition, increased expression of myelination genes of sialic acid metabolism in the hippocampus and ganglioside biosynthesis. Thus, if these data would be confirmed, sialic acid supplementation in neonatal FM could support preterm brain development [49].

The role of HMOs in stimulating gut maturation, acting as prebiotics and immunomodulators, and potentially reducing the occurrence of NEC led to the consideration that their supplementation could be useful in preterm neonates. However, some animal models evidenced that the efficacy of HMOs supplementation requires further investigation, even taking into account the timing of supplementation, the gut immaturity and feeding intolerance [50].

Metabolomics also result useful to evaluate the effects of BM compounds on bacterial growth. According to recent in vitro findings, the growth of Lactobacillus reuteri DSM 17938 is higher in BM than in FM. BM promotes LR 17938-associated metabolites, as reported by the up-regulation of specific metabolites, enhancing its growth and physiological effects [51].

Capillary electrophoresis and time-of-flight mass spectrometry (CETOFMS) has been also applied to analyze the network occurring between the intestinal microbiome and the host metabolites in mice, helping in the characterization of gut metabolism [52].

The high number of experiments and studies focusing on metabolomic BM analysis underline the importance of such models to describe BM micronutrients, the effects of BM or FM supplementation and potentially related outcomes. 


\section{MATERNAL FACTORS}

The influence on maternal factors on BM production are widely investigated.

The application of metabolomics gave interesting results on maternal urine, pointing out metabolites associated with maternal possibility to breastfed and an adequate BM production [53]. Very promising results, in this field, can be obtained by the application of metabolomics on BM samples.

Maternal ethnicity and its influence on BM metabolome was also investigated by Gay et al. [23], analyzing $n=109$ BM samples, at one month postpartum, from five countries (Australia $n=29$, Japan $n=12$, USA $n=18$, Norway $n=40$, and South Africa $n=10$ ). Samples underwent ${ }^{1} H-N M R$. Among $n=28$ identified metabolites, sugars (fucose, glucose, lactose), amino acids (alanine, glutamine, glutamate, glycine, isoleucine, leucine, valine), choline and energy metabolites (acetone, citrate, creatine, creatine phosphate, creatinine, lactate, 2-oxoglutarate, pyruvate, succinate) were detected. The highest variation occurred among South African samples, compared with Norwegian or Australian mothers. In detail, three clusters of milk separation were shown: Black, Caucasian and Asian.

In South African mothers, lactose, 2-oxoglutarate, citrate, creatine, creatine-phosphate, creatinine, betaine and glycerol-phosphocholine showed higher levels than Norwegian (and, except for 2oxoglurate and glycerol-phosphocholine, than Australian samples).

Glucose, fucose content and other energy metabolites (i.e., succinate) did not show significant regional variations.

Glutamine resulted significantly lower in Norwegian versus US women. In Japanese women, significantly higher levels of pyruvate and lactate than Norwegian women were detected. Methanol was significantly lower in Norway BM samples than other countries.

Lactate differentiated Asian samples; 2-Oxoglutarate, creatine, creatine phosphate, creatinine, betaine and glycerophosphocholine were higher while valine was lower in Black population. Glutamate, glutamine, glucose, and phosphocholine characterized Caucasian samples, which resulted less rich in lactate and fucose than Asian samples.

Differences in these milk metabolites occurred according to geographic variations. According to these authors, BM is influenced by regional maternal diet, health status, genetics and breastfeeding practices [23].

Grapov and colleagues [54] pointed out interesting results analyzing BM samples (1-3 days of lactation, colostrum) in mothers affected by gestational diabetes mellitus (GDM) ( $n=6)$ and comparing it to $n=12$ healthy mothers. High-resolution, high-mass accuracy liquid chromatography tandem mass spectrometry LC-MS detected $n=601$ proteins; $n=27$ resulted the best indicators of GDM. Among these, $n=10$ proteins were statistically significantly different in GDM samples versus healthy mothers. Thus, GDM changes colostrum proteome, especially 
regarding proteins with nutritional and immunity roles and potentially influencing neonatal outcome [54].

Finally, we present a very interesting report evaluating breastfeeding safety and BM metabolic composition during acute kidney injury (AKI) [55] in $n=1$ mother aged 35 year who, due to the occurrence of a postpartum hemorrhage, underwent a computer tomography (CT) and administration of a contrast dye on the $1^{\text {st }}$ day postpartum, showing AKI. This is the first study investigating such topic; guidelines regarding breastfeeding recommendations in AKI or chronic kidney disease (CKD) are lacking. ${ }^{1} \mathrm{H}-\mathrm{NMR}$ was applied to compare $\mathrm{BM}$ samples from $\mathrm{n}=1 \mathrm{AKI}$ lactating mother to $n=1$ healthy control. AKI mother started hemodialysis (HD) on day 4 postpartum. BM samples were obtained on day 1 and 4 (before HD in AKI mother) and on day 4 in healthy mother.

BM from AKI mother on day 4 showed lower levels of alanine, glutamine, glutamate, glycine, valine, glucose, citrate, glycerol, phosphocholine, and valerate similar levels of lactose and more maltose, creatinine, hippurate, creatine, creatine phosphate, acetone, choline and pyruvate than healthy control. No difference occurred in fatty acids (FAs). Moreover, AKI milk on day 4 showed a higher $\mathrm{Ph}$.

Finally, authors underline that iodinaxol level significantly decreased from day one to day 4 postpartum ( 55 to $28 \mathrm{mg} / \mathrm{mL}$ ). From these data, it can be deduced that AKI can change BM composition, especially reducing amino acid concentrations and increasing catabolites, not affecting major nutrients content (lactose and lipids).

Moreover, dye radio contrast for CT does not significantly accumulate in BM (only low levels), thus breastfeeding seems safe also after a procedure involving CT dye contrast maternal administration even in case of AKI. Breastfed neonate exposure was low even in case of maternal impaired renal excretion. These interesting results should be proved on larger cohorts [55].

\section{BREAST MILK OLIGOSACCHARIDES AND SECRETOR STATUS}

HMOs are a complex family of soluble unconjugated glycans. Such structures are highly represented in BM and show a higher inter-individual variability; moreover, they exert positive effects on neonate and lactating mother.

HMOs can shape neonatal gut microbiome and metabolome in a cross-feeding mechanism, promoting the growth of commensal species, can modulate neonatal intestinal mucosa and its maturation and also improve immune system, protecting against infections [40,56].

Metabolomic investigation of HMOs will improve the characterization of such structures, the factors influencing their variability and, due to their absence in bovine-derived formulations, the potential benefits related to HMOs supplementation in FM. 
$\mathrm{BM}$ analysis can also allow the distinction of lactating mothers in Secretors $(\mathrm{Se}+)$ and non Secretors (Se-), depending on maternal expression of alpha-1-2-fucosyltransferase (codified by secretor gene, FUT2) and alpha-1-3-4-fucosyltransferase (codified by Lewis gene, FUT3); thus, maternal phenotypes can be: Se+/Le+, Se+/Le-, Se-/Le+, and Se-/Le-, determining significant differences in BM composition (especially HMOs) [54,57].

Metabolomics can be applied to evaluate HMOs content in BM and to obtain information regarding maternal secretor status. In a recent study of our research group [57], n=58 BM samples of colostrum (on the $4^{\text {th }}$ day of lactation) from $n=58$ full-term delivering mothers were evaluated with ${ }^{1} \mathrm{H}-\mathrm{NMR}$. Then, three subgroups were performed, according to neonatal BW: $\mathrm{n}=48$ appropriate for GA (AGA) neonates, $n=2$ large for $G A(L G A), n=10$ small for $G A(S G A)$.

From the analysis, two groups were clearly distinguished based on their HMOs content. One group of samples contained more $\alpha 1,3 / 4-$ linked fucosyl-oligosaccharides, with fucose linked only by $\alpha 1,3$ or $\alpha 1,4$ glycosidic bonds (while $\alpha 1,2$ fucosyloligosaccharides were lacking); In the second group a1,2 fucosyloligosaccharide units were abundant: these two groups corresponded to Se- and Se+ groups respectively. Moreover, the study does not report significant differences in HMOs according to GA, birth weight (BW), delivery mode and gender [57].

The proportion of women classified as secretors was also influenced by ethnicity and ranged from $65 \%$ in Gambia and Ethiopia to $98 \%$ in Peru. The percentage of secretors in the cohort in Peru (98\%) was also higher than Ghana and Washington, USA (68\%) but similar to the cohort in California, USA (95\%) [58].

A recent study explored the influence of maternal geographic provenience and mode of delivery on BM components, through nuclear magnetic resonance spectroscopy ( $\left.{ }^{1} \mathrm{H}-\mathrm{NMR}\right)$, also evaluating the modulation occurring on BM microbiome. $N=79$ healthy lactating mothers from Finland $(n=20)$, Spain $(n=20)$, South Africa $(n=19)$, and China $(n=20)$ were enrolled [25].

Then, they were classified depending on delivery mode: vaginal delivery ( $n=10$ for each country) or caesarean section ( $n=10$ for China, Finland, and Spain; $n=9$ for South Africa).

A global number of $n=68$ different metabolites was detected in $M M$, at one month of lactation. Among these, $n=23$ were amino acids, $n=18$ sugars, $n=10$ lipids and FAs metabolites, $n=7$ energy related metabolites and the other were vitamins or nucleic acids, microbial metabolites or food additives. Metabolomic results were highly influenced by geographical provenience. Variating levels of galactose, lacto-N-fucopentaose III (LNFP III), lacto-N-fucopentaose I (LNFP I) and 2'fucosyllactose (2'FL), 3'-fucosyllactose (3' FL), lacto-N-difucohexaose II (LNDFH II), , 2hydroxybutyrate, 3-hydroxybutyrate, proline, $\mathrm{N}$-acetyl lysine, methyl-histidine, dimethylamine, kynurenine, urea, creatine and creatine phosphate, formate, lactate, acetate, phosphocholine, acetylcholine, low density lipoproteins (LDL), very low density lipoproteins (VLDL), ethanolamine, riboflavin, hippurate, spermidine, spermine and uridine were evidenced. 
Among the interesting findings of such study, the authors underline that Chinese mothers showed significantly higher levels of 3'FL and LNFP III instead Finland samples.

LNFP I was higher in Finland mothers, 2'FL, Short-chain fatty acids (SCFAs), acetate and formate in Spain samples, 3'FL and LNFP III in South Africa and China, respectively. LDL and VLDL were significantly higher in Spain and Finland samples.

Moreover, delivery mode greatly influences BM metabolome. $\mathrm{N}=6$ metabolites showed statistically different levels in mothers undergone vaginal delivery. Among these mothers, higher levels of 3hydroxybutyrate and LNFP III and a lower content of butyrate, ethanolamine, proline and urea were reported.

Interestingly, it was also observed that the effect played by cesarean section is modulated by geographical location. Finally, according to these data, BM metabolome highly influences microbial communities, through several interaction patterns. Such study highlights interesting results; Proteobacteria spp., Actinobacteria spp., and Bacilli spp. seem mostly influenced by BM metabolome.

The results of these studies may improve personalized strategies in neonatal nutrition, also regarding bioactive components [25].

\section{BREAST MILK CHARACTERIZATION}

\subsection{Factors affecting breast milk composition}

\subsubsection{Breast milk relation with prematurity and lactation stage}

Metabolomic analysis of BM from mothers delivering pre-term provides many information regarding the composition of BM, explaining how it modifies itself to satisfy premature newborn's necessities or explaining potential nutritional deficiencies. This knowledge could improve a personalized nutrition.

The study of Perrone and co-workers [59] evaluated BM differences between full-term and preterm delivering mothers and the modifications of such metabolic pathways during lactation. Through ${ }^{1} \mathrm{H}-\mathrm{NMR}$, a total of $\mathrm{n}=30$ samples ( $\mathrm{n}=18$ mothers) were analyzed. Among them, $n=12$ delivered full-term ( $n=12$ samples collected at $4-7$ days of lactation) and $n=6$ delivered pre-term (29-31 w of GA. N=3 samples from each mother, at 1-3 w of lactation).

The two categories were characterized by two different metabolic profiles; in detail, lactose (4.46 ppm) and HMOs, especially those fucosylated, such as fucose (1.23 ppm), N-acetyl-neuraminic acid (2.06 ppm) and $\mathrm{N}$-acetyl-glucosamine (2.04 ppm), were significantly higher in pre-term samples. 
Moreover, although BM metabolome varies during lactation, it was shown that at three weeks of post-natal age it is not equal to full-term samples, showing higher levels of lactose and HMOs [59]. Metabolomics changes over lactation were also evaluated on a single-patient based study [5]. ${ }^{1} \mathrm{H}$ NMR analysis was performed on $n=15$ BM samples collected from the same mother $(n=1)$ twice a day on the days $9,12,24,31,60,85,86$ and 87 of lactation. The results showed a clear separation between the samples collected in the early lactation (9-24 days) and late lactation (31-87 days); the changes could be related to different neonatal needs during growth.

The late stage was characterized by an increase in lactose, choline, alanine, glutamate, glutamine, butyrate and formate levels and a reduction in citrate, phosphocholine, glycerophosphocholine and $\mathrm{N}$-acetylglucosamine [60].

In a cohort of Chinese women, changes in BM metabolome across lactation stages were detected through high-performance liquid chromatography-quadrupole-time of flight mass spectrometry (HPLC-QTOFMS) and analyzed according to maternal diet. By Li and co-workers [61], samples were collected from $n=30$ mothers at days 1 (colostrum), 14 days (transition milk$\mathrm{TM})$ and 42 (MM) post-partum.

As result, $n=84$ metabolites were measured in the three lactation phases. Among them, $n=12$ were fatty acyls, $n=15$ glycerolipids, $n=23$ glycerophospholipids, $n=7$ sphingolipids, $n=7$ vitamins, $n=5$ nucleotides-related metabolites, $\mathrm{n}=2$ amino acids, $\mathrm{n}=1$ amino acid metabolite, $\mathrm{n}=9$ dipeptides, $\mathrm{n}=1$ steroid hormones, $n=1$ energy-related metabolite and $n=1$ amine.

Samples belonging to the three lactation stages were clearly different when analyzed according to metabolomics. As demonstrated, metabolites' variations did not depend on maternal dietary intake. Moreover, some findings resulted quite different from the trends demonstrated in western populations, underlining the role of metabolomics also in revealing geographic or maternal genetic predisposition.

In detail, glycyl-valine, histidinyl-threonine, lysyl-threonine, threoninyl-tyrosine, tyrosyl-glutamine, tyrosyl-serine, valylvaline, valyl-alanine, histidinyl-histidine, tryptophan, histidine, C10:0, C11:0, C14:0, C16:1n-7, C17:0, C18:1n-9, C18:2n-6, prostaglandin E3, octadecanamide, CE (15:1), CE (14:0), monoglyceride (15:0), diacylglycerols (14:0/20:4n-6, 14:0/24:1n-9, 14:1n-5/18:3n-3, 15:0/20:1n-9, 15:0/20:2n-6, 18:0/18:1n-9, 18:4n-3/18:4n-3, 20:0/24:1n-9, 24:0/15:0, 18:3n-3/18:3n3, 15:0/16:1n-7 and 14:0/14:1n-5), triacylglycerols (15:0/14:0/15:0 and 16:0/14:0/16:0), lysophosphatidylcholines (18:2n-6 and 18:4n-3), lysophosphatidyl-ethanolamines (20:2n-6, 15:0), phosphatidylcholine (18:0/18:2n-6), phosphatidylethanolamines $(20: 5 n-3 / 16: 0,18: 2 n-6 / 14: 1 n-5$, 18:1n-9/24:1n-9, 18:4n- 3/18:4n-3 and 16:1n-7/18:0), phosphatidylserines (14:1n-5/18:3n-3 and 14:0/18:1n-9), phosphatidic acid (15:0/14:0), phosphatidylglycerophosphate (18:1n-9/18:2n-6), sphingosine, phytosphingosine, sphinganine, ceramide-Cer (d18:0/24:0), Cer (d18:0/22:0), glucosylceramide (d18:1/12:0), SM (d18:0/18:0), 6-succinoaminopurine, deoxyuridine, deoxyuridine monophosphate (dUMP), purine, AMP 3'-phosphate, vitamin D3, 1,24,25-(OH)3 
vitamin D3, 25- hydroxyvitamin D2-25-glucuronide, vitamin D2, biotin, $11 \beta$ - hydroxyprogesterone, cis-Aconitic acid and spermidine increased with BM maturation.

On the contrary, C14:1n-5, lysophosphatidylcholines (22:6n-3, 16:0 and 22:5n-3), lysophosphatidyl-ethanolamines (20:4n-6, 20:3n-6 and 22:0), phosphatidylethanolamines (14:0/14:1n-5 and 15:0/14:1n-5), phosphatidic acid (14:1n-5/22:6n- 3), retinoyl $\beta$-Glucuronide and $\mathrm{Y}$-tocopherol were more abundant in colostrum [61].

Sundekilde et al. [62], firstly investigated and compared metabolic profiles of BM samples collected from pre-term and full-term delivering mothers, according to GA at delivery and lactation phase.

According to their ${ }^{1} \mathrm{H}$-NMR results, BM for pre-term newborns is significantly different from full-term (depending on GA) and BM metabolome varies across lactation. Changes determine a realignment of pre-term samples to full-term after 5-7 weeks, independently from GA at birth.

Samples were constituted by colostrum, $<5$ days post-partum $(n=5)$, TM, 6 days -2 w post-partum $(n=4)$ and $M M,>2 w(n=21)$. A total of $n=92$ samples were analyzed according to lactation phase; Samples were collected from $n=45$ mothers, $n=30$ delivering full-term and $n=15$ delivering pre-term $(<37 \mathrm{w})$. Several metabolic differences occurred among colostrum, TM and MM.

In colostrum of full-term delivering mothers higher levels of valine, leucine, betaine, and creatinine were found, instead of MM. Glutamate, caprylate, and caprate were higher full-term MM than colostrum. In pre-term colostrum, increased levels of oligosaccharides, citrate and creatinine were found.

Levels of caprylate, caprate, valine, leucine, butyrate, alanine, glutamate, pantothenate 3-FL, lacto$\mathrm{N}$-difucohexaose I (LNDFH I) and lactic acid increased across lactation.

Levels of fucosylated oligosaccharides, fucose, $\mathrm{N}$-acetylneuraminic acid, $\mathrm{N}$-acetylglucosamine, valine, leucine, pantothenate, citric acid, lactic acid, choline, betaine ,creatinine fucosyl moieties, $\mathrm{N}$-acetylneuraminic acid, $\mathrm{N}$-acetylglucosamine, 3'-sialyllactose (3'SL), 6'-sialyllactose (6'SL) and 2'FL were higher in colostrum and decreased during milk maturation.

Most discriminating metabolites between full-term and pre-term BM samples were carnitine, caprylate, caprate, pantothenate, urea, lactose, HMOs, citrate, phosphocholine, choline and formate.

Citrate, lactose, phosphocholine, fucosyl moieties, $\mathrm{N}$-acetylneuraminic acid, $\mathrm{N}$-acetylglucosamine, 3'SL, 6'SL, LNDFH I, glutamate, citric acid, phosphocholine, choline and formic acid were higher in pre-term milk samples, while carnitine, caprylate, caprate, pantothenate, beta-hydroxybutyrate and urea were higher in full-term samples [62].

A comparison between dynamic changes of BM composition during the first month of lactation in full-term and pre-term samples was also performed by Spevacek and colleagues [20]. ${ }^{1} \mathrm{H}-\mathrm{NMR}$ was applied to investigate samples of colostrum (day 0-5 of lactation), TM (day 14), and MM (day 28) collected from $n=15$ full-term $(>37 w)$ and $n=13$ preterm $(<37 \mathrm{w})$ delivering mothers. 
From this analysis, $n=69$ metabolites were detected. In detail, $n=15$ were sugars, $n=23$ amino acids and derivatives, $n=11$ energy-related metabolites, $n=10$ fatty acid-associated metabolites, $\mathrm{n}=3$ nucleotides, $\mathrm{n}=2$ vitamins, and $\mathrm{n}=5$ bacteria-related metabolites.

Colostrum and MM showed a different clusterization. Some metabolites were higher in MM, pointing out an increasing trend during lactation.

Regarding sugars, most HMOs decreased during lactation. Total HMOs and neutral HMOs, 2'-FL, 3'-galactosyllactose (3'-GSL), 3'-SL, 6'-SL, fucose, LNFP III and Lacto-N-neotetraose (LnNT) showed higher levels in full-term colostrum. LNFPII and lactose resulted higher in preterm MM than colostrum; 3-FL, glucose, lactose were higher in full-term MM. Moreover, in this sample, $\mathrm{N}=10$ fullterm delivering and $n=10$ preterm delivering mothers resulted $\mathrm{Se}+$.

Among aminoacids, alanine was higher in preterm MM. 2-Aminobutyrate, alanine, carnitine, glutamate, glutamine, histidine, urea and valine were higher in full-term MM, while acetylcarnitine, betaine, isoleucine, lysine and taurine were higher in full-term colostrum.

Also FAs associated metabolites showed interesting trends; azelate, butyrate, caprylate, Glycero3-phosphocholine were higher in preterm MM, decreasing during lactation.

Butyrate, azelate, caprate, caprylate, ethanolamine, glycero-3-phosphocholine were higher in fullterm MM, while choline and myo-Inositol were higher in full-term colostrum.

Regarding energy-related metabolites, acetone, creatinine and creatine phosphate resulted higher in full-term MM; 2-Oxoglutarate, creatine, fumarate, lactate and pyruvate were higher in full-term colostrum. 2-oxoglutarate, acetone, lactate and pyruvate were higher in preterm MM. Among nucleotides, adenosine monophosphate (AMP) was higher in full-term mature milk and hypoxanthine was higher in full-term colostrum.

Investigating bacteria related metabolites, it was shown that acetoin increased in preterm MM, dimethyl-sulfone increased in full-term MM and was lower in preterm MM while hyppurate and methanol were higher in full-term colostrum and lower in preterm colostrum.

As result, it can be concluded that BM metabolites vary during the first month of lactation and the highest variability has been shown in pre-term samples [20].

The interesting study of Andreas et al. [63], performed a combined multiplatform approach, using HPLC-MS, LC-MS, GC-MS, capillary electrophoresis-mass spectrometry (CE-MS) and ${ }^{1} \mathrm{H}-\mathrm{NMR}$ to evaluate $n=70$ BM samples. They were collected from $n=57$ lactating mothers delivering full-term. Sampling occurred between 2-80 days of lactation. Globally, $n=710$ metabolites were identified and compared during three time intervals: $1-5$ days, $6-10$ days and $>10$ days of lactation. Most variable metabolites during lactation were lactose, fucose, di- and triacylglycerols, aminoacids and short and medium chain FAs, since a gradual increase occurred during lactation. These metabolites are involved in immunological, neurological, and gastrointestinal neonatal development. Moreover, they represent energy sources. 
On the contrary, several HMOs, phosphocholines citrate and pyruvate decreased during lactation. It is interesting to underline that BM maturation depends on neonatal needs; during lactation, it increase its energy content, lipids and carbohydrates. Moreover, maternal factors affecting BM composition should be fully clarified [63].

In a recent study, Bzikowska-Jura and co-workers [64] investigated FAs levels in BM, determining omega-3 FA content in relation to maternal current dietary intake. $N=32$ samples from $n=32$ women during the first month of lactation were analyzed with GC-MS. They all assumed adequate levels of foods containing omega-3 FAs.

As result, current dietary intake of omega-3 FAs was not significantly correlated with BM content, while their habitual intake could influence BM levels. Nutritional habits in the three months prior delivery mainly affect BM [64].

In a preliminary study, the research group of Cagliari and Turin performed a comparative study evaluating BM metabolome in two categories of pre-term samples (extremely preterm: 23-28 weeks of GA vs moderate preterm: 32-34 weeks). By comparing colostrum, TM and MM, metabolic variations were more evident in the first phases of lactation than in MM. In detail, in these preliminary data, variations in colostrum mostly regarded choline and derivatives metabolites; this is not a surprising result, because choline is a component of cerebral membranes and its high level could be related protect and promote the development of our most important organ: the brain [65].

An interesting study evaluated the effects of BM composition at 1 and 4 months of lactation on infant lipid and amino acids serum metabolism. $\mathrm{N}=196$ dyads of mothers and newborns were enrolled [66].

BM was analyzed with GC-MS for macronutrients and FA content. Phospholipids, acylcarnitines, and amino acids were then analyzed in serum samples collected from infants at 4 month of age. As result, the authors observed that BM components evaluated in this study have a small impact on infants' serum metabolites. Lyso-phosphatidylcholine (LPC) in serum correlates with BM FAs and protein content, especially LPC 14:0 (previously associated to growth improvement and obesity risk increase) [66]. This is an example of a complementary approach (simultaneous BM and serum metabolome) to evaluate the effects of nutrition on neonatal metabolic status. In conclusion, these findings point out a great variability of BM metabolites during different phases of lactation and according to neonatal GA, probably meeting the specific requirements of each newborn. It is not easy to detect specific metabolites increasing or decreasing in each of the examined categories and characterizing every phase of lactation, due to the lack of a precise standardization among the groups, regarding GA, ethnicity, detection methods and other potential confounding factors. However, trying to summarize the mentioned studies, we could state that preterm milk samples seems to contain higher levels of lactose, some HMOs (especially fucose, Nacetyl-neuraminic acid, N-acetyl-glucosamine, fucosyl moieties, 3'SL, 6'SL, LNDFH I), citrate, 
creatinine, phosphocholine, choline, glutamate, citric acid, and formic acid. In preterm MM, the increase in LNFPII, lactose, alanine, zelate, butyrate, caprylate, glycero-3-phosphocholine, oxoglutarate, acetone, lactate, and pyruvate seems significant, even if all the exact consequences on the outcome of premature neonates are not currently exploited. In our opinion, such findings highly encourage future studies and research in this direction.

\subsubsection{Breast milk and multiple pregnancies}

A recent investigation performed by our study group investigated BM composition in multiple pregnancies [67], representing about $3 \%$ of all pregnancies. It is well known that multiples often show lower GA and BW than singletons, resulting more vulnerable to several diseases.

BM samples from mothers of $n=19$ couples of twins and $n=5$ triplets ( $G A<33$ weeks [w] and $B W<$ $1500 \mathrm{~g}$ in at least one neonate) were analyzed and compared to a control group of $\mathrm{n}=28$ singletons $(\mathrm{GA} \leq 28 \mathrm{w})$.

Our sample of multiples was composed by $n=51$ neonates ( $n=25$ males and $n=26$ females); Among $n=28$ singletons, $n=13$ were males, $n=15$ females. $B M$ sampling was performed between the $1^{\text {st }}$ and the $20^{\text {th }} \mathrm{W}$ of postnatal life. The total pool of samples from multiples was composed by $\mathrm{n}=103$ samples, weekly obtained to detect variation during lactation.

As result, at $\mathrm{GA} \leq 28$ weeks, it was detected a significantly higher protein content in BM for multiples than singletons ( 1.53 vs $1.29 \mathrm{~g}$ per $100 \mathrm{ml}$ ), while lactose content was significantly higher in BM for singletons (6.72 vs $6.34 \mathrm{~g}$ per $100 \mathrm{ml}$ ) [67]. Lactose acts as an osmotic agent to draw additional fluid into milk secretory vesicles and in turn could increase milk yield in case of breastfeeding challenge as it is the case in multiple pregnancies [68].

GA was the factor mostly influencing BM protein content: in fact, a significant inverse correlation occurred between the weeks of corrected GA and proteins. Regarding other components, no significant modification was detected over time [67].

To the best of our knowledge, BM metabolites in mothers delivering multiples has not been adequately investigated. In literature, we found a single old study measuring proteins, lactose, and FAs content in BM samples collected from eight women breastfeeding twins and one woman breastfeeding a triplet [69].

The higher protein content that our group found in BM from mothers delivering preterm multiples could face the needs of such vulnerable category, promoting and sustaining growth and organ development. These findings could help in the improvement of nutritional strategies and BM individualized fortification.

A very recently published Spanish survey investigates several maternal and neonatal variables influencing breastfeeding length in a large cohort of very low birth weight (VLBW) neonates, including both multiples and singletons. This study, pointing out numerous factors interfering with 
in-hospital maternal BM feeding, could help in the identification of practices that might be improved to avoid early breastfeeding cessation, especially in preterm multiples [70].

\subsection{Recent studies investigating breast milk bioactive components}

\subsubsection{Proresolution activity}

BM contains significant levels of specialized pro-resolving mediators (SRM) involved in host defense and anti-inflammation. Twenty bioactive compounds (e.g. resolvins, protectins, maresins, lipoxins and prostanoids) that belong to lipoxygenase (LOX) and cyclooxygenase (COX) pathways were detected in MM from a small sample of four healthy donors. In addition, the results showed higher levels of proinflammatory mediators (leukotriene B4-LTB4 and prostanoids) and lower levels of SPM in BM from mother with mastitis [71].

\subsubsection{Antiviral activity}

The possible presence of maternal viruses in BM can determine the transmission to breastfed neonates. I.e., maternal Cytomegalovirus (CMV) can undergo periodical reactivations, even in case of maternal immunity. This BM-acquired infection can lead to a severe disease, especially in premature newborns.

According to recent data, metabolomics analysis of amniotic fluid (AF) and maternal urines seems very useful in the description of neonatal susceptibility to CMV infection and providing information regarding the transmission and the severity of disease [72-74].

In the next future, metabolomics BM analysis could improve our knowledge in the field.

\subsubsection{Endogenous mediators}

Endocannabinoids and related compounds (endocannabinoid metabolome, ECM) represent endogenous mediators originating from long-chain PUFAs and have been detected in BM, as confirmed by a recent study of Gaitan et al [24].

The mechanisms of action and the role of BM ECM are not fully understood; according to a recent data, the mediator arachidonoylglycerol seem modulate the type 1 cannabinoid receptor in neonatal brain; moreover, bioactive BM constituents may also play a role in infant health and development. Here, it could influence the suckling response during lactation. Samples from n=24 lactating mothers were collected and analyzed with LC-MS. ECM was evaluated in TM and MM, to detect its variation across lactation. 
As principal results, variable levels of arachidonoylethanolamine, palmitoylethanolamine, oleoylethanolamine, docosahexaenoylethanolamine, eicoapentaenoylethanolamine, eicosenoylethanolamine, arachidonoylglycerol, palmitoyglycerol, oleoylglycerol, docosahexaenoylglycerol, eicosapentaenoylglycerol, eiconenooylglycerol, arachidonic acid, docosahexaenoic acid, and eicosapentaenoic acid were reported. Docosahexaenoylglycerol (DHEA) showed significantly different levels between the two stages of lactation (higher in TM) [24].

\subsection{Breast milk compared with other milk sources, formula milk and bovine samples}

To better understand the right fit between milk components and infant needs it is important to know the specific lipids and protein requirements of newborns and children. Fat intake in infants, which is high during the breastfeeding period, can gradually decrease in the second half of the first year of life, from the start of the complementary feeding period up to three years of age: $40 \%$ of total dietary energy in the 6 to 12 months period and 35 to $40 \%$ in the $2^{\text {nd }}$ and $3^{\text {rd }}$ year of life. Fat intakes below $25 \%$ of total dietary energy have been associated with low vitamin levels in some young children. The concept of protein requirement includes both total Nitrogen and indispensable amino acid requirements. The quantity and usage of indispensable amino acids is considered to be an indicator of the dietary protein quality, which is usually assessed using the Protein Digestibility Corrected Amino Acid Score (PD-CAAS). For infants, children and adolescents, the WHO/FAO/UNU (2007) estimated that the protein requirements from six months to adulthood were derived factorially as the sum of requirements for maintenance and growth corrected for efficiency of protein use. An average maintenance value of $0.66 \mathrm{~g}$ protein $/ \mathrm{kg}$ body weight per day was applied. Average daily needs for dietary protein for growth were estimated from average daily rates of protein deposition, calculated from studies on whole-body potassium deposition, and from an efficiency of use of dietary protein for growth of $58 \%$. The PRI was estimated based on the average requirement plus 1.96 SD using a combined SD for growth and maintenance [75]. Metabolomics analysis of BM, FM and bovine samples may provide interesting findings, as reported by several studies, pointing out a higher interindividual variability and changes occurring according to several partially known factors [34].

Recent studies evaluated this topic. Scano and co-workers [76] compared $n=31$ BM samples collected between 3-26 w of lactation (from full-term delivering mothers) to eight different kinds of FM ( $n=31$ samples; among these, $n=17$ FM for infants aged 0-6 months and $n=14>6$ months) through gas chromatography-mass spectrometry (GC-MS).

As result, metabolites found only in FM were orotic acid and isomaltulose $189.8 \mathrm{mg} / \mathrm{dL}$. Malic acid, sugars (glucose $122.8 \mathrm{mg} / \mathrm{dL}$, fructose and galactose) and mannitol $27.6 \mathrm{mg} / \mathrm{dL}$ were higher in such samples. BM showed higher levels of amino acid (threonine, valine, alanine, serine, glutamic 
acid $82.7 \mathrm{mg} / \mathrm{dL}$, glycine, and pyroglutamic acid $47.9 \mathrm{mg} / \mathrm{dL}$ ), urea, and inositols (myo-inositol $46.1 \mathrm{mg} / \mathrm{dL}$ and scylloinositol). According to thesa data, metabolome of FM samples is highly different from BM and varies according to the kind of analyzed formula, while no significant differences occurred between first infant formulas and follow-up formulas [76]. Lopes et al. [77] focused the attention on lipid profile of BM vs FM, evaluating it with ${ }^{1} \mathrm{H}-\mathrm{NMR}$. $\mathrm{N}=12$ commercial FM samples and $\mathrm{n}=10 \mathrm{BM}$ samples from different mothers were compared. It was pointed out that FM shows a significantly lower content of saturated fatty acids (SFAs), higher content of unsaturated FAs (UFAs, $38.20 \%$ vs $30.59 \%$ ) and a comparable polyunsaturated fatty acid (PUFA $9.92 \%$ vs $17.96 \%$ ) level instead of BM. BM samples were characterized by a higher content of SFAs in the sn-2 position (26.03\% vs $2.93 \%)$ and PUFAs in the sn-1,3 position $(15.35 \%$ vs $3.94 \%)$ instead of FM. On the contrary, FM showed SFAs esterified mainly in the sn1,3 position ( 33.07 vs $4.93 \%$ ) and PUFAs in the sn- 2 position ( $9.57 \%$ vs $7.05 \%$ ) instead of BM. Thus, both kind of samples show similar lipid profiles, but the most important difference was the stereospecific FAs distribution. Moreover, the levels of vegetables, fish, microalgae oil and raw materials were also measured in FM, to characterize in a better way its lipid composition [77]. A comparative approach was used by Quian and co-workers [78], comparing BM metabolic profile to FM and bovine milk. Gas chromatography-time-of-flight mass spectrometry (GC-TOFMS) and ultra-performance liquid chromatography-quadrupole-time-of-flight mass spectrometry (UPLCQTOFMS) were performed. $\mathrm{N}=30 \mathrm{BM}$ samples were obtained from $\mathrm{n}=30$ lactating mothers. Moreover, $n=20$ bovine samples and $n=20$ FM samples were investigated.

As result, BM, FM and bovine samples were clearly distinct. It was shown that BM was characterized by higher levels of non-esterified SFAs with aliphatic tails $<16$ carbons (potentially reflecting triglycerides' hydrolysis), monounsaturated and PUFAs and lower levels of tricarboxylic acids (TCA) intermediates when compared with FM and bovine samples.

Mostly varying metabolites belonged to the following classes: non-esterified fatty acids (NEFAs), free amino acids (FAAs), TCA intermediates, and free carbohydrates.

NEFAs, including SFAs, MUFAs and PUFAs were more complex in BM samples. Among the NEFAs, palmitic and stearic acid represented two exceptions, being lower in BM. In each sample type, free amino acids and carbohydrates showed unique prophiles.

In BM, higher of non-esterified myristoleic acid (14C:1), palmitoleic acid (16C:1), oleic acid (C18:1) and eicosenoic acid (C20:1), linoleic acid (C18:2) and alpha-linolenic acid (C18:3), eicosapentaenoic acid (C20:5), docosapentaenoic acid (C22:5) , docosahexaenoic acid (C22:6), gamma-linolenic acid (C18:3), eicosadienoic acid (C20:2), eicosatrienoic acid (C20:3), arachidonic acid (C20:4) and docosadienoic acid (C22:2) were detected. Moreover, a higher aboundance of 5oxoproline, alanine, arginine, glutamic acid, glutamine, glycine, serine, taurine, tyrosine, valine and fucose was pointed out. Lower levels of phenylalanine, histidine and taurine, proline, TCA intermediates, including 2-ketoglutaric acid, 2-ketoglutaramic acid, citric acid and fumaric acid, 2- 
ketoglutaramic acid, cis-aconitic acid and malic acid characterized BM samples. In addition, BM was lower in arabinose, mannose, glucosamine and acetylglucosamine, fructose, maltose and threitol [78].

Another metabolic comparison between BM and bovine milk was performed by Liang and colleagues [79], using isobaric tags for relative and absolute quantification technology combined with liquid chromatography tandem mass spectrometry (iTRAQ technology combined with LC-MS detection). The authors measured the levels of free and hydrolytic amino acids in $n=30$ samples of BM collected from $n=30$ Chinese mothers between 7 and 14 days post-partum and compared them to $\mathrm{n}=30$ bovine samples.

As result, it was reported a total free amino acid content of $0.32 \mathrm{~g} / \mathrm{L}$ in bovine milk and $0.63 \mathrm{~g} / \mathrm{L}$ in $\mathrm{BM}$ and a content of total hydrolytic amino acids of $4.2 \mathrm{~g} / \mathrm{L}$ and $2.2 \mathrm{~g} / \mathrm{L}$ respectively. Moreover, amino acid content in BM was more abundant and highly varied.

From metabolomics analysis, BM and bovine samples underwent a clear separation; $\mathrm{N}=42$ amino acids were detected: $n=27$ showed higher levels in $B M$ than bovine samples.

Human BM samples resulted rich in histidine, leucine, lysine, phenylalanine, citrulline, 1-Methyl-Lhistidine, glutamic acid, glutamine, threonine, serine and glycine.

Asparagine, aspartic acid and cysteine were exclusively detected in BM. Bovine samples contained high levels of isoleucine, leucine, valine, histidine, methionine, valine, threonine, arginine, tyrosine, $\gamma$-amino-butyric acid, taurine, $\alpha$-aminobutyric acid, phenylalanine, ethanolamine and glycine [79].

By these studies, it can be concluded that BM, FM and bovine milk have their peculiar metabolic profile, which result unique for each milk type. Improving our knowledge on this topic, through metabolomics, will help to ameliorate commercial FM and dairy products composition, potentially resembling in the most accurate way BM components.

A unique and recent preliminary investigation by our study group, compared metabolomics profiles of $n=15$ different kinds of FM (among these, $n=6$ organic -bio formulas) and BM (using ${ }^{1} \mathrm{H}-\mathrm{NMR}$ ). Among the interesting obtained results, it emerged that methionine is significantly higher in organic -bio formulas (about 3 folds higher) than conventional FM [80]. It is interesting to underline that methionine is involved in methylation processes, fundamental in the establishment of epigenetic patterns.

The recent findings of Odintsova et al., investigating methylation pathways in buccal cells of children, allows to conclude that breastfeeding, and potentially the metabolic composition of FM, could influence epigenetic pathways in middle-infancy [81]. 


\section{BREASTFEEDING RELATED TO GROWTH}

BM metabolomic analysis can be also used to evaluate the effects of each component on neonatal and infantile outcome, with promising results.

The effect of each mother's BM lipidome was recently correlated to the growth pattern in a cohort of premature neonates [82]. $\mathrm{N}=26$ preterm neonates born between 26-36 w of GA and fed with their mother's BM were enrolled; among them, $n=11$ underwent a "faster" growth pattern while $\mathrm{n}=15$ a "slower" growth.

Samples were collected between 2 and 7 weeks of lactation. The evaluation of lipid species performed with LC-MS showed a clear separation between samples belonging to these different groups, especially in samples collected between 2 and 4 weeks of lactation.

BM samples of infants belonging to the "faster" group contained more total fats $(4.75 \mathrm{~g} / 100 \mathrm{~mL}$ vs $3.55 \mathrm{~g} / 100 \mathrm{~mL}$ ), medium-chain SFAs, sphingomyelin, dihomo-linolenic acid (DGLA)-containing phosphethanolamine, total SFAs (free and triglycerides- and phospholipids-bound FAs), mediumchain SAT (MCSAT), n-3 long-chain PUFA, such as docosahexanoic acid, eicosapentaenoic and docosapentaenoic acids, medium- or long-chain sphingomyelins-SM and Cer [such as Cer (d18:1/24:0), SM(d18:0/12:0)], several phosphatidylcholines, phosphatidylethanolamines or plasmalogen-derivatives containing palmitic (C16:0) or palmitoleic (C16:1) acid [such as PE (16:0/16:1), PE (16:1/20:0)], stearic (C18:0) or oleic (C18:1) acid [such as PC (18:0/18:1), PC (18:0/18:2) and PE (O-18:0/20:5)], DGLA, C20:3, [PE (20:3/22:6), PE (22:0/20:3)], or docosahexaenoic acid (DHA, C22:6) [PE (20:3/22:6)].

"Faster" sample contained less oleic acid, oleic acid-containing triglyceride and DGLA-oxylipin, total MUFAs, long-chain triglycerides (TG) containing oleic acid (C18:1) [such as TG (18:1/18:1/18:2), TG (16:0/17:1/18:1) and TG (18:0/18:1/18:1)], eicosanoids, including many DGLA-derived oxylipins [15S-HpEDE, 11-deoxy-16, 16-dimethyland 9-deoxy-9-methylene-16,16dimethyl-PGE2], Lyso-phospholipids (LysoPS) [LysoPS (22:0) and LysoPG (22:4)].

Among the $n=162$ lipids discriminating the two classes of samples, $n=9$ resulted the best predictors of neonatal weight growth. I.e., medium-chain sphingomyelin [SM (d18:0/12:0)], phospholipid containing DGLA and DHA [PE (20:3/22:6)], DGLA-derived oxylipin, TG-containing oleic acid (TG (16:0/17:1/18:1), TG (18:0/18:1/18:1)) and MCSAT, resulted strongly associated with neonatal growth, probably depending on their involvement in energy production, reduction of oxidative stress, modulation of gastrointestinal inflammation. Moreover, oxylipin is a bioactive component involved in neonatal metabolism and outcome [82].

Through a successive study, the same authors globally evaluated metabolome, lipidome, glycome, FAs, and free amino acids in samples collected from the same cohort study ("faster" vs "slower" growth), during the first month of life, describing a clear separation between the two categories [83]. 
In BM collected from the "faster" growth group, higher levels of essential amino acid total content, especially branched-chain, insulinotrophic and gluconeogenic amino acids (BCAA), arginine and tyrosine, lacto- $\mathrm{N}$-fucopentaose, choline, hydroxybutyrate, orotic acid, nicotinamide, hydroxybutyric acid, pyruvic and citraconic acids, were pointed out.

Lower levels of glycine and taurine, glutamate, glutamine, sulfur amino acid content (taurine and methionine) cresol and benzoic acid were also detected.

Regarding HMOs content, samples were adjunctively divided according to maternal $\mathrm{Se}+(\mathrm{n}=21)$ or Se- $(n=5)$ status.

In "faster" samples, higher levels of total fucosylated HMOs, especially LNFPI, di-fucosylated HMOs, an isomer of LNDFH and neutral HMOs such as lacto-N-hexaose (pLNH) were detected.

On the contrary, neutral HMO 3000 and di-fucosylated HMO 4210b were lower.

Some HMOs (LNFPI and 4210d, 4230b and 4230c) and amino acids (valine, glycine) seem predictive of a "slower" growth.

LNFP I, LNDFH, 3'FL and pLNH were highly predictive only in Se+ mothers, while di-fucosylated HMOs (4230c, 4230b, 4240b, and 4210d) were predictors independently by Sectetor status. Regarding lipidomics, medium-chain saturated fatty acids (MCSAT such as pentadecanoic and myristic acid), TG (TG(46:0) and TG(50:2)), phospholipids (PS(38:4) and $P E(38: 3)$ ) seem characterize the "faster" group.

On the contrary, oleic acid, plasmalogen-derivatives (PC(P-34:2) and $\mathrm{PE}(\mathrm{P}-36: 0))$, lysophosphatidylethanolamine-containing arachidonic acid (LysoPE(20:4)), Cer (Cer(18:1/22:0)) and very long-chain TG (TG(54:4) and TG(58:7)) seem indicate a "slower" growth.

The most relevant metabolites predicting an optimal growth resulted: arginine-creatinine pathway, aromatic amino acid metabolism, nicotinamide adenine dinucleotide precursors, sulfur metabolism, oligosaccharides, mitochondrial fatty acid beta-oxidation, pyruvic, citraconic and aconitic acids, arginine, tyrosine, hydroxy-3-methylbutyric acid, undecenal, dodecanedioic acid and choline, 3hydroxycapric acid, dihydrocaffeic acid 3-O-glucuronide, LNFPII, 9-undecenal, heptanoyl- and hexanoyl-glycine, 3-hydroxy-adipic acid, valerenic acid.

From these results, it can be deduced that BM samples in the "faster" growth group is more adequate to sustain preterm newborns' development, containing more energy, more digestible calories for immature gastrointestinal system, a higher proportion of aminoacids promoting protein synthesis, bioactive molecules preventing NEC, promoting immune system development and improving neonatal outcome [83].

The study of Cheatham and co-workers [84] investigated the potential correlation between some BM compounds (lutein, choline and DHA) and infant cognitive outcome (in detail, recognition memory abilities at six months of age measured by an electrophysiological assessment).

The authors report data belonging to $n=55$ participants; BM samples were obtained between three and five months of lactation. HPLC was used for detection. As result, a synergistic increase in 
choline and lutein levels, as well as the increase in choline and DHA, resulted associated to better recognition memory.

These nutrients, taken together, seem to act synergistically in the brain, sustaining the development of such organ and cognitive improvement [84].

\section{MICRONUTRIENTS LEVEL ASSESSMENT}

According to recent data, OMICS technologies seem able to investigate the effects and efficacy of micronutrients (MN) supplementation and dietary interventions, even in the periconceptional period.

The average $\mathrm{MN}$ values in $\mathrm{BM}$ are related to maternal intake, even if it is not exactly known what level of maternal intake is adequate to satisfy neonatal needs [85]. The content of several Vitamins (such as Vitamin D, Vitamin A and water-soluble vitamins) reflects the diet of the mother. Breastfed infants of mothers following a strict vegan diet are at high risk of severe megaloblastic anemia and neurological deficit because of Vitamin B12 deficiency. The ESPGHAN recommends supplementation of breastfed infants or their breastfeeding mothers with Vitamin B12 if lactating mother follows a vegan diet [86].

In this regard, according to Hampel and co-workers, UPLC-MS can perform the simultaneous determination of thiamin, riboflavin, niacin, vitamin B6, Vitamins $A$ and $E$ in $B M$; moreover, iron, copper and zinc can be measured through coupled plasma atomic emission spectroscopy $[87,88]$. Through these technologies, it was pointed out a high variation on BM MN content among different mothers, especially belonging to different populations; moreover, values resulted lower than infants' requirements. Metabolomics also provides information regarding the efficacy of supplementation; interestingly, the interference of some drugs with $\mathrm{MN}$ levels can be determined, such as the effects of antiretroviral drugs that can reduce some MN levels [89].

In detail, the study of Hampel and colleagues [87] aimed to determine if a reduced maternal intake of B-vitamins during lactation could determine infant deficiency, with potential clinical manifestations.

UPLC-MS was used to detect thiamin, riboflavin, flavin adenine dinucleotide (FAD), nicotinamide and pyridoxal $(P L)$ on $n=80$ BM samples collected from mothers living in Cameroon, China, India, Malawi and the USA during the first month of lactation.

It was shown that thiamin, niacin and B-6 levels increased during lactation. Significant differences occurred depending on geographic origins, especially regarding vitamin B-2 and niacin.

The USA samples showed significantly higher levels of nicotinamide. Pyridoxal was significantly lower in samples from Malawi and USA. High levels of thiamin in the Cameroon samples might depend on the later stage of lactation. Variation depending on the geographic origin are mostly 
related to differences in diet and fortification. Since the samples were collected at different lactation stages, the influence of such variability on vitamin level should be taken into account [87].

\section{BREAST MILK CONTAMINANTS}

The presence of contaminants in BM can influence neonatal outcome. According to recent data, metabolomics represents a promising tool to explore the levels of such contaminants and define BM safety.

Persistent organic pollutants (POPs), such as organochlorine pesticides (OCPs), organophosphate pesticides (OPPs), polychlorinated biphenyls (PCBs) and polychlorinated dibenzo-p-dioxins (dioxins), are synthetic environmental chemicals which can be absorbed by inhalation, ingestion or dermal contact by lactating mothers and potentially excreted in BM. Even if the exact mechanism is not fully exploited, they can interfere with endocrine systems and impair neonatal neurodevelopment. Du and colleagues [90] performed the first longitudinal study investigating pesticides' concentration in BM, its modifications during the first year of lactation and neonatal daily pesticides' intake. These values have been analyzed together with infants' growth outcome and maternal characteristics.

$N=99 B M$ samples were collected from $n=16$ mothers living in Western Australia at 2, 5, 9 and 12 months of lactation and the levels of 88 pesticides were analyzed with GC-MS/MS. Among these, only $n=3(3.4 \%)$ were detected: $p, p^{\prime}$-dichlorodiphenyldichloroethylene (p,p'-DDE), p,p'dichlorodiphenyltrichloroethane ( $\left.p, p^{\prime}-\mathrm{DDT}\right)$ and beta-Hexachlorocyclohexane $(\beta-\mathrm{HCH}) . P, p^{\prime}-\mathrm{DDE}$, the most abundant, was detected in $n=83$ samples $(83 \%)$ and showed a mean concentration of $52.25 \pm 49.88 \mathrm{ng} / \mathrm{g}$ fat, p,p'-DDT $27.67 \pm 20.96 \mathrm{ng} / \mathrm{g}$ fat and $\beta-\mathrm{HCH} 48.00 \pm 22.46 \mathrm{ng} / \mathrm{g}$ fat. These concentrations significantly decreased along the first year of lactation.

$P, p$-DDE was not significantly correlated with infant growth outcomes and finally, neonatal daily DDTs intake was 14-1000 times lower than the threshold reference values and decreased significantly throughout the first 12 months of lactation [90].

In a subsequent study, the same group investigated pesticide concentrations in a higher group of West Australian mothers $(n=40)$ at the same lactation points $(2,5,9$ or 12 months), through GCMS [91]. P,p'-DDE was detected at trace levels, showing a mean concentration of $62.8 \pm 54.5 \mathrm{ng} / \mathrm{g}$. It did not result associated with infant growth outcomes such as weight, length, head circumference and percentage fat mass. Moreover, breastfed infant daily intake resulted at least 59 fold below the tolerable daily intake (TDI) recommendations [91].

Another group validated HPLC coupled to electrospray mass spectrometry (HPLC-ESI-MS) to detect BM levels of selective serotonin reuptake inhibitors-SSRI (citalopram, fluoxetine, fluvoxamine, paroxetine and sertraline and their major metabolites desmethylcitalopram and norfluoxetine) [92]. In mothers affected by postpartum depressive symptoms, or previously treated 
and continuing drug administration during lactation, these drugs may pass through breastfeeding and negatively affect neonatal outcome.

This innovative analytical method could allow the simultaneous detection of all SSRI drugs and their metabolites. From each SSRI-treated mothers, $n=2$ BM samples were collected during the $1^{\text {st }}$ and/or $4^{\text {th }}$ w postpartum.

After the detection of BM SSRI levels, the relative infant circulating dose (RID) can be obtained, to predict the possible occurrence of adverse effects (generally not expected if RID is lower than $10 \%)$, except in newborns at higher risk of drug accumulation or exposed to multiple drugs. Although this is an ongoing study and complete results will be published in the next future, RID ranges between $0.5 \%$ and $9 \%$ have been reported [92].

An interesting study investigating BM contaminants was performed by Braun and co-workers [93]. Mycotoxins, secondary metabolites produced by several moulds, including Aspergillus, Fusarium and Penicillium species may contaminate many agricultural products.

The most common mycotoxins are aflatoxins (AFs), fumonisins (FBs), ochratoxin A (OTA), zearalenone (ZEN) and trichothecenes. Among the side effects of these substances, a correlation with neural tube defects, stunting, esophageal cancer, breast cancer and kidney toxicity was reported. Moreover, they act as endocrine disruptor.

Since the possible transfer to breastfed infant, it must be also underlined that early mycotoxins exposure during the first phases of life can impair short- and long-term outcomes and should be limited in this vulnerable period.

LC-MS/MS has been applied to analyze $n=75$ BM samples from $n=22$ Nigerian mothers, assessing the levels of 28 mycotoxins (including aflatoxins, ochratoxin A, deoxynivalenol, zearalenone) and their metabolites.

As result, it was observed that many samples were not contaminated or minimally contaminated with beauvericin (56\%), enniatins B (9\%), OTA (15\%) and aflatoxin M1 (1\%). Beauvericin, not previously reported, was the most abundant (up to $0.019 \mathrm{ng} / \mathrm{mL}$ ). It can be concluded that tolerable daily intakes have not been exceeded but further studies are needed on this topic [93].

A recent field of metabolomics application is the analysis of adulterants in BM, potentially occurring in the recently popular market of such biofluid.

Soy, almond, cow, goat milk and infant formula could be added to dilute BM. This could not be so safe and a method to detect contaminants would be needed. In a recent study, a high performance chemical isotope labeling (CIL) LC-MS platform was applied to analyze the metabolome of an unknown milk sample, comparing it to human $\mathrm{BM}(\mathrm{N}=10$ samples of $\mathrm{BM}$ were collected at various lactation times) [94]. According to the similitude, the authors differentiated the six different kind of samples as follows. $\mathrm{N}=1043$ metabolites were detected in $\mathrm{BM}, \mathrm{n}=2925$ metabolites in goat milk (among these, $n=834$ in common with BM), $n=2670$ in cow milk ( $n=851$ in common with $B M)$, $n=1348$ in almond milk ( $n=488$ in common with $B M), n=2562$ in soy milk ( $n=583$ in common with 
BM), $n=1553$ in FM ( $n=518$ in common with BM). The results of this study show that although in the amine/phenol metabolomes of human, soy, almond, cow, goat and infant FM there are many common metabolites, there is a large number of unique metabolites specific for each kind of milk. Thus, this method is able to detect metabolomic differences between non-adulterated BM and BM containing $5 \%$ or more potential milk adulterant and could be also applied to other fluids [94]. In a recent interesting study, BM environmental chemical toxicants have been measured and correlated to modifications in neonatal gut microbiome at 1 month of life [95]; BM samples from $\mathrm{n}=267$ Norwegian mothers were collected each morning for eight consecutive days, between 2 weeks and 2 months postpartum and $n=28$ chemical exposures were measured. Liquid-liquid extraction and GC-MS and high-performance LC-MS were used.

It was reported that environmental toxicants in $\mathrm{BM}$, notably polybrominated flame retardants (especially PBDE-28), Perfluorooctanoic acid (PFOA), surfactant perfluorooctanesulfonic acid (PFOS), and dioxin-like polychlorinated biphenyls (especially PCB-167), are associated with less microbiome diversity and negatively influence infant gut microbial composition during the critical neonatal period [95].

\section{METABOLIC EFFECTS OF DIFFERENT NEONATAL NUTRITION STRATEGIES}

Metabolomic differences occurring in neonates fed with BM and FM can be investigated through urine, feces and blood samples, as recently reviewed by Phan et al. [96].

The obtained results pointed out the importance of metabolomics in the evaluation of neonatal diet, pointing out the differences occurring between BM and FM fed subjects, the potential metabolic implications of a nutritional deficiency, therefore helping in the improvement of FM composition.

\subsection{Serum metabolome according to neonatal nutrition}

From a recent study, it can be stated that lipid biomarkers in neonatal serum (detected through infusion high-resolution mass spectrometry) could be useful to understand neonatal nutrition regimen, differentiating BM fed from FM fed infants at 3-6 months of age. Lipidomic profiles compared between the two groups pointed out the presence of phosphatidylcholine $\mathrm{PC}(35: 2)$, and two sphingomyelins $\operatorname{SM}(36: 2)$ and $\operatorname{SM}(39: 1)$, whose variations seems to correlate to the different nutrition pattern [97].

\subsection{Urinary metabolome according to neonatal nutrition}

Several studies applied metabolomics analysis to neonatal urine to evaluate the effects associated to different nutritional strategies. 
In the study of Cesare-Marincola et al. [98], urinary metabolome of BM neonates was compared to urine samples of subjects fed with two different kind of FM. In the three groups, urinary metabolome changes were mostly influenced by infant growth than the dietary regimen. Similar temporal trends of choline, betaine, myo-inositol, taurine, and citrate levels occurred. Some differences characterized metabolic profile of breastfed neonates, while variations were not detected between subjects fed with the two types of FM. In detail, a two-fold increase characterized the levels of citric acid and fucosyl- compounds in infants fed with BM. In neonates fed with FM, a two-fold increase characterized pantothenic acid, while a three-fold increase was observed in tartaric acid levels, compared by box-whisker plot analysis [98].

Moreover, another study evaluated urinary metabolomics according to neonatal nutrition in the following groups: intrauterine growth restriction (IUGR), LGA, and AGA neonates. Through GCMS, interesting findings were pointed out. In fact, at birth, IUGR and LGA neonates' metabolome was different from that of AGA. However, after three days of alimentation, metabolome variation was dependent on nutritional regimen. In detail, higher levels of glucose, galactose, glycine, myoinositol, aconitic acid, aminomalonic acid and adipic acid were detected in BM fed neonates [99]. The role of neonatal nutrition on urinary metabolome was also confirmed in a recent study detecting lower levels of 8-hydroxy-20-deoxyguanosine, a marker of oxidative DNA damage, choline, choline metabolites, lactic acid, PGD2 and markers of insulin sensitivity in BM fed neonates than FM. On the contrary, surprisingly, atherosclerotic indices were significantly higher in breastfed neonates [100].

\subsection{Fecal metabolome according to neonatal nutrition}

Three recent studies applied metabolomics to detect fecal changes according to neonatal nutrition. Chow and co-workers [101], through GC-MS and LC-MS on fecal samples, detected higher levels of $n=14$ compounds including HMOs, linoelaidate and myo-inositol in neonates assuming BM $(n=4)$; on the contrary, in the stools of neonates assuming FM $(n=4)$, higher levels of $n=41$ metabolites can be considered indicators of carbon limitation and protein fermentation [101]. In the trial of Liu et al. [102], subjects from 7 to 90 days of postnatal life were enrolled and fed with BM or two different kind of FM. Metabolomic results obtained from fecal analysis evidenced higher levels of Bifidobacteria spp. and acetic acid in breastfed neonates and in those fed with Synlait Pure Canterbury Stage 1 infant formula (SPCF).

Thus, fecal bacterial composition and SCFAs were comparable in subjects fed with BM and SPCF, contrarily with what reported in rats [102].

Finally, Bazanella and co-workers [103] aimed to evaluate metabolic changes in stools of infants fed with BM, FM an FM supplemented with Bifidobacteria spp. during the $1^{\text {st }}$ year of life and through HPLC-MS. 
In subjects belonging to the $3^{\text {rd }}$ group, lower levels of Bacteroides spp. and Blautia spp. and variations in lipids and unknown metabolites levels were detected. At 1 month, significant differences were also evident between BM an FM fed subjects [103].

Thus, fecal metabolomics could improve our knowledge regarding the interaction occurring among diet, intestinal microbiome and the host.

\section{RECENT PROGRESSES}

Due to the complex composition of BM, metabolomic sample analysis requires complexes extraction methods and analytical platforms. New methods are constantly introduced and innovations in metabolomics contribute to improve sensibility of these techniques and accuracy of results.

In example, liquid-liquid extraction (LLE) and solid-phase extraction (SPE) techniques have been combined to perform a semiquantitative analysis of lipids through LC-MS. Thus, an extensive dynamic metabolome coverage, especially for low-abundance glycerophospholipids and sphingolipids, was obtained [104].

Moreover, a novel method to analyze TG fraction in BM samples has been recently applied; Liquid Extraction Surface Analysis coupled to Fourier Transform Mass Spectrometry (LESA-MS) allowed molecular profiling. The technique based on Collision-Induced Dissociation (CID) was recently used to profile fatty acid residues. Thus, the presence of very long chain fatty acids (C26:0 and C26:1), not previously reported, has been detected [105].

Lipids constitute about $5 \%$ of BM. Since its important role in infant nutrition, their characterization is very useful; however, lipid fraction is highly variable; thus, analysis and standardization is difficult. The introduction of new chromatographic techniques, such as liquid and supercritical fluid chromatography, as well as mass spectrometry, allow a better characterization of BM lipidome [106].

According to another study, the Biocrates AbsoluteIDQR p180 kit for human milk metabolomics (detecting 40 acylcarnitines, 42 acids/biogenic amines, 91 phospholipids, 15 sphingolipids) can be used for human BM analysis and plasma evaluation, providing comparable and homogeneous results [107].

Regarding next future progresses, the paper of Minegishi et al. describes the importance of the innovative Tohoku Medical Megabank biobank (TMM biobank), representing the first major population-based biobank in Japan. In this structure, there are 3.4 million tubes of biospecimens and associated health and analytic data belonging to about 150,000 TMM cohort participants. Samples include peripheral and cord blood mononuclear cells, buffy coat, plasma, serum, urine, breast milk and saliva and are indispensable for academic, clinical and industrial research even for metabolomics studies [108]. 


\section{PASTEURIZATION EFFECTS}

Donor human milk (DM) could be very useful for neonates whose mother can not supply with their own milk.

Serveral treatments can be performed to ensure BM microbiological safety, even if they can affect its composition and impair nutritional or biological properties.

Holder pasteurization is the process currently recommended in Human Milk Banks (HMBs); in NUCUs, BM freezing is also common.

Both act on BM oxidative stress [109].

The effects of pasteurization and cold storage on BM has been investigated through several studies, evidencing different levels of BM alteration [110-112].

Many data also report the beneficial effects of DM on preterm infants.

The effects of pasteurization and refrigeration on oxidative stress and biological BM properties should be further evaluated and metabolomics could help to describe accurately such processes [109].

\section{CONCLUSIONS}

Metabolomic analysis of BM is currently a topic of great interest and several studies have been performed in the last years, to evaluate and describe the fluid more recommended for neonatal nutrition.

Such OMICS technology, not invasively performed, allows a detailed description of BM components, investigating their dependence on maternal or environmental factors, perinatal events and neonatal characteristics; moreover, the possible roles of each component and potentially related neonatal and infantile outcomes can be investigated.

Highly interesting is the possible detection of BM changes during lactation, understanding its modification according to neonatal requests during growth and development.

The dependence of BM composition according to GA at birth allows the description of BM modifications in mothers delivering preterm neonates, producing BM susceptible to higher variability, or, as recently reported by our research group, in mothers delivering multiples. Maternal factors affecting BM composition including genetics, geographical proveniences, diet, delivery mode or diseases such as gestational diabetes mellitus or mastitis can be also evaluated through metabolomics.

Metabolic evaluation is also helpful in describing the effects of BM components on gut microbiome of breastfed infant, detecting the interplays occurring between milk metabolites, gut bacteria and host metabolites (including HMOs). 
A clear and well defined correlation between each metabolite and its health outcome is not currently available; however, we are working at the creation of specific atlas dealing with metabolites and their involvement in several diseases and conditions, in pediatrics and especially in neonatology [113].

Moreover, metabolomics also results useful to investigate BM micronutrients levels (to highlight the necessity of supplementation), the level of contaminants and pesticides (to attest BM safety for breastfed neonates) and is also able to detect the levels of maternal drugs potentially transferred with breastfeeding.

The effects of several treatments on milk samples (including pasteurization or freezing), to investigate potential impairment of BM or FM potentialities, can be also performed through a metabolomics approach.

Improving all this knowledge will provide a global picture of how BM components interacts and how they change across lactation, to sustain neonatal growth and improve short-long-term outcomes. In detail, growth outcomes and neurodevelopment seem highly correlated with BM melabolome. Moreover, a deeper description of BM composition will enable the production of FM more appropriate as possible for each neonate, i.e. through the supplementation with metabolites, probiotics, prebiotics or more.

More biofluids can be contemporarily investigated (i.e. BM and neonatal biofluids), to investigate potential direct effects of nutrition on neonatal metabolome.

Due to the extraordinary inter-individual variability, each neonate or infant is unique. A central point in personalized nutrition could be the tailoring on each person, influencing neonatal outcome, also taking into account the effects played by BM on neonatal gut microbiome.

Since a single metabolomics platform is not sufficient to globally describe each constituents of a biofluid, several studies underline the importance of an integrated approach based on the combination of several techniques; a great number of studies underline the importance of new approaches or more innovative techniques to improve the accuracy of BM analysis.

\section{EXPERT OPINION:}

Due to the great progresses of medical research and the interesting results published in the last years, we ought that the next future could be based on a "personalized" and "tailored" nutrition, according to each subjects' needs. In this direction, metabolomics is giving fundamental opportunities, representing a versatile tool in several fields of medicine, including neonatal nutrition and breastfeeding.

By an accurate analysis of all the available studies, it is now clear that each neonate can not be analyzed individually, being part of a complex dyad in which he is closely connected to his mother. In this perspective, it would be extremely relevant to perform a global investigations of such 
biofluids or tissues representing a direct interface between mother and newborn, such as placenta, umbilical cord, amniotic fluid or breast milk, whose function has been compared since ancient times to maternal blood, providing to the neonate nutrients but also bioactive components and cellular elements even after birth.

In this review, we analyzed in depth the potential application of metabolomics analysis to maternal $\mathrm{BM}$, in relation to several maternal, perinatal, neonatal or environmental conditions.

In addition, we underline that BM evaluation should be put in relation with the analysis of other neonatal fluids, such as urines, feces or blood, to directly investigate metabolic pathways related to different metabolites in BM of FM and therefor triggered by different kinds of neonatal nutrition. Taking into account the concept of mother-child dyad, relevant information could also be obtained by the analysis of maternal biofluids, due to the high influence of maternal factors on BM constituents.

It is now clear that one of metabolomics goals would be an easy integration of several analytic platforms, providing a detailed and complete description of the analyzed samples, even if the high costs of such techniques and the needs of highly specialized operators could represent a great limitation in the diffusion of such methods.

In the microbiomics era, it is widely known that metabolomics is a fundamental instrument, able to detect the effects of metabolites on microbiome composition, such as BM metabolites effects on maternal "lactobiome" and on neonatal gut microbiome, representing the linking ring among microbial communities and the interactions occurring with the host.

We ought to underline that despite the numerous studies reported in the field, many efforts are still needed to obtain a better standardization of the population studied and the samples collected and, primarily, many studies are required to identify all the possible clinical effects and implications of detected metabolites.

If the entity and the meaning of each metabolite variation should be clarified in a direct and univocal way, the results obtained through metabolomics analysis would provide reliable, reproducible, standardized and safe data in each clinical setting, allowing the pediatrician or neonatologist to orient his clinical and therapeutic practice according to metabolic findings. To further simplify such process, the use of less complex platforms would be desirable. In our opinion, in five or ten years, several progresses could be obtained in this direction. The ideal strategy, could be the introduction of metabolomics sticks, potentially accurate and cheap, to investigate neonatal biofluids in a short time and allowing an innovative and personalized therapeutic management. 


\section{Funding}

This paper was not funded.

\section{Disclosure statement}

The authors have no relevant affiliations or financial involvement with any organization or entity with a financial interest in or financial conflict with the subject matter or materials discussed in the manuscript. This includes employment, consultancies, honoraria, stock ownership or options, expert testimony, grants or patents received or pending, or royalties.

\section{Reviewer disclosures}

Peer reviewers on this manuscript have no relevant financial or other relationships to disclose. 


\section{REFERENCES}

Papers of special note have been highlighted as:

* of interest

** of considerable interest

1. American Academy of Paediatrics. Breastfeeding and use of human milk. Pediatrics. 2012;129:e827.

2. Mazurier E, Rigourf V, Perez $P$, et al. Effects of maternal supplementation with omega-3 precursors on human milk composition. J Hum Lact. 2017; 33(2):319-28.

3. Smilowitz JT, O'Sullivan A, Barile D, et al. The Human Milk Metabolome Reveals Diverse Oligosaccharide Profiles. J Nutr. 2013;143(11):1709-18.

4. W.H.O. Short-term effects of breastfeeding: a systematic review on the benefits of breastfeeding on diarrhoea and pneumonia mortality. Geneva, Switzerland: 2013. ISBN: 9789241506120.

5. W.H.O. Long-term effects of breastfeeding: a systematic review. Geneva, Switzerland: 2013. ISBN: 9789241505307.

6. Butts CA, Hedderley DI, Herath TD et al. Human milk compositions and dietary intake of breastfeeding women of different ethnicity from the Manawatu-Wanganui Region of New Zeland. Nutrients. 2018;10(9):1231.

7. WHO. 10 Facts on Breastfeeding. Available online: http://www.who.int/features/ factfiles/breastfeeding/en/ (accessed on 22 February 2018). 7.

8. Chantry CJ, Eglash A, Labbok M. ABM Position on Breastfeeding-Revised 2015. Breastfeed Med. 2015;10(9):407-11.

9. Ip S, Chung M, Raman G, et al. Breastfeeding and maternal and infant health outcomes in developed countries. Evid Rep Technol Assess. 2007;153:1-186.

10. Kjos SL, Henry O, Lee RM, et al. The effect of lactation on glucose and lipid metabolism in women with recent gestational diabetes. Obstet Gynecol. 1993;82(3):451-5.

11. McManus RM, Cunningham I, Watson A, et al. Beta-cell function and visceral fat in lactating women with a history of gestational diabetes. Metabolism. 2001;50(6):715-9.

12. Butte NF, Hopkinson JM, Mehta N, et al. Adjustments in energy expenditure and substrate utilization during late pregnancy and lactation. Am J Clin Nutr. 1999;69(2):299-307.

13. De Silva A, Jones PW, Spencer SA. Does human milk reduce infection rate in preterm infants? A systematic review. Arch Dis Child Fetal Neonatal Ed. 2004;89:509-13.

14. Wolker A. Breast milk as the gold standard for the protective nutrients. J pediatr. 2010;156(2):3-7.

15. Owen CG, Martin R, Whincup P, et al. Effect of infant feeding on the risk of obesity across the life course: a quantitative review of published evidence. Pediatrics. 2005;115(5):1367-77. 
16. Owen CG, Martin RM, Whincup PH, et al. Does breastfeeding influence risk of type 2 diabetes in later life? A quantitative analysis of published evidence. Am J Clin Nutr. 2006;84(5):1043-54. 17. Arenz S, Ruckerl R, Koletzko B, et al. Breast-feeding and childhood obesity - a systematic review. Int J Obes Relat Metab Disord. 2004;28(10):1247-56.

18. Bardanzellu F, Fanos V , Reali A. Omics" in Human Colostrum and Mature Milk: Looking to Old Data with New Eyes". Nutrients. 2017;9(8):E843.

19. Bertino E, Giuliani F, Baricco M et al. Benefits of donor milk in the feeding of preterm infants. Early Hum Dev. 2013;89(2):S3-6.

20. Spevacek AR, Smilowitz JT, Chin EL' et al. Infant Maturity at Birth Reveals Minor Differences in the Maternal Milk Metabolome in the First Month of Lactation. J Nutr. 2015;145(8):1698-708

21. Garwolinska D, Namiesnik J, Kot-Wasik A, et al. Chemistry of the human breast milk: a comprehensive review of the composition and the role of the milk metabolites in child development. J Agric Food Chem. 2018;66(45):11881-96.

22. Dritsakou K, Liosis G, Valsami G, et al. The impact of maternal and neonatal-associated factors on human milk's macronutrients and energy. J Matern-Fetal Neonatal Med. 2017;30(11):1302-8.

*23. Gay MCL, Koleva PT, Slupsky CM, et al. Worldwide Variation in Human Milk Metabolome: Indicators of Breast Physiology and Maternal Lifestyle? Nutrients. 2018;10(9):E1151.

* Interesting study comparing BM metabolome in mothers from five different countries.

24. Gaitán AV, Wood JT, Zhang F, et al. Endocannabinoid Metabolome Characterization of Transitional and Mature Human Milk. Nutrients. 2018;10(9):E1294.

25. Gómez-Gallego C, Morales JM, Monleón D, et al. Human Breast Milk NMR Metabolomic Profile across Specific Geographical Locations and Its Association with the Milk Microbiota. Nutrients. 2018;10(10):E1355.

26. de Figueiredo CS, Palhares DB, Melnikov P, et al. Zinc and copper concentrations in human preterm milk. Biol Trace Elem Res. 2010;136(1):1-7.

27. O'Brien CE, Krebs NF, Westcott JL, et al. Relationships among plasma zinc, plasma prolactin, milk transfer, and milk zinc in lactating women. J Hum Lact. 2007; 23(2):179-83.

28. Bertino E, Di Nicola $P$, Giuliani F, et al. Benefits of human milk in preterm infant feeding. JPNIM. 2012;1(1):19-24.

29. Carraro S, Giordano G, Reniero F, et al. Metabolomics: a new frontier for research in pediatrics. J Pediatr. 2009;154(5):638-64.

30. Burgess K, Rankin N, Weidt S. Metabolomics. Handbook of Pharmacogenomics and stratified medicine, Academic Press. 2014;10:181-201.

31. Emwas AH, Roy R, McKay RT, et al. NMR Spectroscopy for Metabolomics Research. Metabolites. 2019;9(7):pii:E123. 
32. Baharum SN, Azizan KA. Metabolomics in Systems Biology. Adv Exp Med Biol. 2018;1102:5168.

33. Khandelwal $P$, Andersen $H$, Romick-Rosendale L, et al. A Pilot Study of Human Milk to Reduce Intestinal Inflammation After Bone Marrow Transplant. Breastfeed Med. 2019;14(3):193-202.

**34. Cesare Marincola F, Noto A, Caboni P, et al. A metabolomic study of preterm human and formula milk by high resolution NMR and GC/MSanalysis: preliminary results. J Matern Fetal Neonatal Med. 2012;25(5):62-7.

** The first study investigating BM metabolome.

35. Praticò G, Capuani G, Tomassini A, et al. Exploring human breast milk composition by NMRbased metabolomics. Nat Prod Res. 2014; 28:95-101.

36. Villaseñor A, Garcia-Perez I, Garcia A, et al Breast milk metabolome characterization in a single-phase extraction, multiplatform analytical approach. Anal Chem. 2014;86(16):8245-52.

37. Longini M, Tataranno ML, Proietti F, et al. A metabolomic study of preterm and term human and formula milk by proton MRS analysis: preliminary results. J Matern Fetal Neonatal Med. 2014;27:27-33.

38. Urbaniak C, McMillan A, Angelini M, et al. Effect of chemotherapy on the microbiota and metabolome of human milk, a case report. Microbiome, 2014;2:24-35.

*39. Cesare Marincola F, Dessì A, Corbu S' et al. Clinical impact of human breast milk metabolomics. Clin Chim Acta. 2015;451(Pt A):103-6.

** The first review resuming available studies on BM metabolomics. This is the article we have uploaded through this review.

40. Bardanzellu F, Fanos V, Strigini FAL, et al. Human Breast Milk: Exploring the Linking Ring Among Emerging Components. Front Pediatr. 2018;6:215.

41. Liu Z, Subbaraj A, Fraser K, et al. Human milk and infant formula differentially alters the microbiota composition and functional gene relative abundance in the small and large intestines in weanling rats. Eur J Nutr. 2019. doi: 10.1007/s00394-019-02062-w [Epub ahead of print].

42. Tsiafoulis CG, Papaemmanouil C, Alivertis D, et al. NMR-Based Metabolomics of the Lipid Fraction of Organic and Conventional Bovine Milk. Molecules. 2019;24(6):E1067.

43. Thomas FC, Mullen W, Tassi R, et al. Mastitomics, the integrated omics of bovine milk in an experimental model of Streptococcus uberis mastitis: 1 . High abundance proteins, acute phase proteins and peptidomics Mol Biosyst. 2016; 12(16):2735-47.

44. Moukarzel S, Dyer RA, Garcia C' et al. Milk Fat Globule Membrane Supplementation in Formula-fed Rat Pups Improves Reflex Development and May Alter Brain Lipid Composition. Sci Rep. 2018;8:15277.

45. Picone G, Zappaterra M, Luise D' et al. Metabolomics characterization of colostrum in three sow breeds and its influences on piglets survival and litter growth rates. J Anim Sci Biotechnol. 2018;9:23. 
46. Hamilton MK, Ronveaux CC, Rust BM, et al. Prebiotic milk oligosaccharides prevent development of obese phenotype, impairment of gut permeability, and microbial dysbiosis in high fat-fed mice. Am J Physiol Gastrointest Liver Physiol. 2017;312(5):G474-87.

47. Charbonneau MR, O'Donnell D, Blanton LV, et al. Sialylated Milk Oligosaccharides Promote Microbiota-Dependent Growth in Models of Infant Undernutrition. Cell. 2016;164(5):859-71. 48. Cowardin CA, Ahern PP, Kung VL, et al. Mechanisms by which sialylated milk oligosaccharides impact bone biology in a gnotobiotic mouse model of infant undernutrition. Proc Natl Acad Sci U S A. 2019;116(24):11988-96.

49. Obelitz-Ryom K, Bering SB, Overgaard SH, et al. Bovine Milk Oligosaccharides with Sialyllactose Improves Cognition in Preterm Pigs. Nutrients. 2019;11(6). pii: E1335.

50. Bering SB. Human Milk Oligosaccharides to Prevent Gut Dysfunction and Necrotizing Enterocolitis in Preterm Neonates. Nutrients. 2018;10(10). pii: E1461.

51. Mai TT, Tran DQ, Roos S, et al. Human Breast Milk Promotes the Secretion of Potentially Beneficial Metabolites by Probiotic Lactobacillus reuteri DSM 17938. Nutrients. 2019;11(7): E1548.

52. Wakita Y, Shimomura Y, Kitada Y, et al. Taxonomic classification for microbiome analysis, which correlates well with the metabolite milieu of the gut. BMC Microbiol. 2018;18(1):188.

53. Sachse D, Bærug A, Sletner L, et al. Urine NMR metabolomics analysis of breastfeeding biomarkers during and after pregnancy in a large prospective cohort study. Scand J Clin Lab Invest. 2014;74(3):264-72.

54. Grapov D, Lemay DG, Weber D, et al. The human colostrum whey proteome is altered in gestational diabetes mellitus. J Proteome Res. 2015;14(19):512-20.

55. Chruscicki A, Morton AR, Akbari A, et al. Composition of human breast milk in acute kidney injury. Obstet Med. 2017;10(2):79-82.

56. Fanos V, Reali A, Marcialis MA, et al. What you have to know about Human Milk Oligosaccharides. J Pediatr Neonat Individual Med. 2018;7(1):e070137.

57. Dessì A, Briana D Corbu S, et al. Metabolomics of Breast Milk: The Importance of Phenotypes. Metabolites. 2018;8(4):E79.

58. McGuire MK, Meehan CL, McGuire MA, et al. What's normal? Oligosaccharide concentrations and profiles in milk produced by healthy women vary geographically. Am J Clin Nutr. 2017;105(5):1086-100.

59. Perrone S' Longini M, Zollino, et al. Breast milk: To each his own. From metabolomic study, evidence of personalized nutrition in preterm infants. Nutrition. 2019;62:158-61.

60. Wu J, Domellöf M, Zivkovic AM, et al. NMR-based metabolite profiling of human milk: A pilot study of methods for investigating compositional changes during lactation. Biochem Biophys Res Commun. 2016;469(3):626-32. 
61. Li K, Jiang J, Xiao H, et al. Changes in the metabolite profile of breast milk over lactation stages and their relationship with dietary intake in Chinese women: HPLC-QTOFMS based metabolomic analysis. Food Funct. 2018;9(10):5189-97.

${ }^{* * 62 . ~ S u n d e k i l d e ~ U K, ~ D o w n e y ~ E, ~ O ' M a h o n y ~ J A, ~ e t ~ a l . ~ T h e ~ E f f e c t ~ o f ~ G e s t a t i o n a l ~ a n d ~ L a c t a t i o n a l ~}$ Age on the Human Milk Metabolome. Nutrients. 2016;8(5):E304.

** The first study investigating metabolic profiles of BM samples from pre-term and full-term delivering mothers, according to GA at delivery and lactation phase

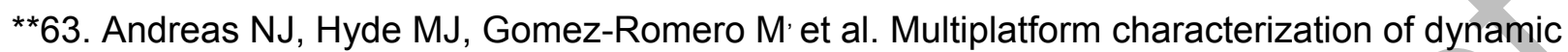
changes in breast milk during lactation. Electrophoresis. 2015;36(18):2269-85.

** Applying a combined multiplatform approach to investigate BM samples

64. Bzikowska-Jura A, Czerwonogrodzka-Senczyna A' Jasińska-Melon E' et al. The Concentration of Omega-3 Fatty Acids in Human Milk is Related to Their Habitual but Not Current Intake. Nutrients. 2019;11(7):E1585.

65. Ghisu, A, Fanos, V. Analisi Metabolomica Longitudinale del Latte di Madri di Neonati Pretermine di Diverse età Gestazionali. Bachelor's Thesis, University of Cagliari, Cagliari, Italy, 2016.

${ }^{*} 66$. Hellmuth $\mathrm{C}$, Uhl O, Demmelmair $\mathrm{H}$, et al. The impact of human breast milk components on the infant metabolism. PLoS ONE. 2018;13(6):e0197713.

* Complementary study evaluating the effects of BM metabolome on infant serum lipids and amino acids

*67. Congiu M, Reali A, Deidda F, et al. Breast Milk for Preterm Multiples: More Proteins, Less Lactose. Twin Res Hum Genet. 2019;22(4):265-71.

* Metabolomic study investigating $\mathrm{Bm}$ in multiple pregnancies.

68. Powe CE, Puopolo KM, Newburg DS, et al. Effects of recombinant human prolactin on breast milk composition. Pediatrics. 2011;127(2):e359-66.

69. Saint L, Maggiore P, Hartmann PE. Yield and nutrient content of milk in eight women breastfeeding twins and one woman breast-feeding triplets. Br J Nutr. 1986;56(1):49-58.

70. Porta R, Capdevila E, Botet F, et al. Breastfeeding Disparities between Multiples and Singletons by NICU Discharge. Nutrients. 2019;11(9):pii:E2191.

71. Arnardottir H, Orr SK, Dalli J, et al. Human milk proresolving mediators stimulate resolution of acute inflammation. Mucosal Immunol. 2016;9(3):757-66.

72. Barberini L, Noto A, Saba L, et al. Multivariate data validation for investigating primary HCMV infection in pregnancy. Data Brief. 2016;9:220-30.

73. Fattuoni $C$, Palmas $F$, Noto $A$, et al. Primary HCMV infection in pregnancy from classic data towards metabolomics: an exploratory analysis. Clin Chim Acta. 2016;460:23-32.

74. Bardanzellu F, Fanos V, Reali A. Human Breast Milk-acquired Cytomegalovirus Infection:

Certainties, Doubts and Perspectives. Curr Pediatr Rev. 2019;15(1):30-41. 
75. EFSA (European Food Safety Authority). Dietary reference values for nutrients: Summary report. EFSA supporting publication. 2017:e15121. 92 pp.

76. Scano P, Murgia A, Demuru M, et al. Metabolite profiles of formula milk compared to breast milk. Food Res Int. 2016;87:76-82.

77. Lopes TIB, Cañedo MC, Oliveira FMP, et al. Toward Precision Nutrition: Commercial Infant Formulas and Human Milk Compared for Stereospecific Distribution of Fatty Acids Using Metabolomics. OMICS. 2018;22(7):484-92.

78. Qian L, Zhao A, Zhang Y et al.

Metabolomic Approaches to Explore Chemical Diversity of Human Breast Milk, Formula Milk and Bovine Milk. Int J Mol Sci. 2016;17(12):E2128.

79. Liang $X$, Han $\mathrm{H}$, Zhao X, et al. Quantitative analysis of amino acids in human and bovine colostrums milk samples through iTRAQ labeling. J Sci Food Agric. 2018;98(13):5157-63. 80. Corbu S, Pintus R, Dessì A, et al. 1H-NMR metabolomics analysis of conventional and organic formula milk: preliminary results. $N^{\circ} 52$, Selected Abstracts of the 15 th International Workshop on Neonatology and the 40th Congress UMEMPS (Union of Middle-Eastern and Mediterranean Pediatric Societies); Cagliari (Italy); October 24th-26th, 2019.

81. Odintsova VV, Hagenbeek FA, Suderman M, et al. DNA Methylation Signatures of Breastfeeding in Buccal Cells Collected in Mid-Childhood. Nutrients. 2019;11(11):pii: E2804.

82. Alexandre-Gouabau MC, Moyon T, Cariou V, et al. Breast Milk Lipidome Is Associated with Early Growth Trajectory in Preterm Infants. Nutrients. 2018;10(2):E164.

*83. Alexandre-Gouabau MC, Moyon T, David-Sochard A, et al. Comprehensive Preterm Breast Milk Metabotype Associated with Optimal Infant Early Growth Pattern. Nutrients. 2019;11(3):E528. * Investigating BM metabolome in relation to the growth pattern of premature neonates 84. Cheatham CL'Sheppard KW. Synergistic Effects of Human Milk Nutrients in the Support of Infant Recognition Memory: An Observational Study. Nutrients. 2015;7(11):9079-95.

85. Biesalski HK, Black RE (eds): Malnutrition and the First 1,000 Days of Life: Causes, Consequences and Solutions. World Rev Nutr Diet. Basel: Karger; 2016. Current Information Gaps in Micronutrient Research, Programs and Policy: How Can We Fill Them? Allen LH. Hidden Hunger. 2016;115:109-17.

86. ESPHGAN Committee on Nutrition. Breast-feeding: A Commentary by the ESPGHAN Committee on Nutrition. JPGN. 2009;49:112-25.

87. Hampel D, York ER, Allen LH. Ultra-performance liquid chromatography tandem massspectrometry (UPLC-MS/MS) for the rapid, simultaneous analysis of thiamin, riboflavin, flavin adenine dinucleotide, nicotinamide and pyridoxal in human milk. J Chromatogr B Analyt Technol Biomed Life Sci. 2012;903:7-13.

88. Hampel D, Shahab-Ferdows S, Domek J, et al. Competitive chemiluminescent enzyme immunoassay for vitamin B12 analysis in human milk. Food Chem. 2014;153:60-5. 
89. Allen L, Hampel D, Shahab-Ferdows S, et al. Antiretroviral therapy provided to HIV-infected Malawian women in a randomized trial diminishes the positive effects of lipid-based nutrient supplements on breast milk B-vitamins. Am J Clin Nutr. 2015;102(6):1468-74.

90. Du J, Gridneva Z, Gay MC, et al. Longitudinal study of pesticide residue levels in human milk from Western Australia during 12months of lactation: Exposure assessment for infants. Sci Rep. 2016;6:38355.

91. Du J, Gridneva Z, Gay MCL, et al Pesticides in human milk of Western Australian women and their influence on infant growth outcomes: A cross-sectional study. Chemosphere. 2017;167:24754.

92. Weisskopf E, Panchaud A, Nguyen KA, et al. Simultaneous determination of selective serotonin reuptake inhibitors and their main metabolites in human breast milk by liquid chromatography-electrospray mass spectrometry. J Chromatogr B Analyt Technol Biomed Life Sci. 2017;1057:101-9.

93. Braun D, Ezekiel CN, Abia WA' et al. Monitoring Early Life Mycotoxin Exposures via LC-MS/MS Breast Milk Analysis. Anal Chem. 2018;90(24):14569-77.

94. Mung D, Li L. Applying quantitative metabolomics based on chemical isotope labeling LC-MS for detecting potential milk adulterant in human milk. Anal Chim Acta. 2018;1001:78-85.

95. Iszatt N, Janssen S, Lenters V, et al. Environmental toxicants in breast milk of Norwegian mothers and gut bacteria composition and metabolites in their infants at 1 month. Microbiome. 2019;7:34.

96. Phan M, Momin SR, Senn MK, et al. Metabolomic Insights into the Effects of Breast Milk Versus Formula Milk Feeding in Infants. Curr Nutr Rep. 2019;8(3):295-306.

97. Acharjee A, Prentice $P$, Acerini $C$, et al. The translation of lipid profiles to nutritional biomarkers in the study of infant metabolism. Metabolomics. 2017;13:25.

98. Cesare Marincola F, Corbu S, Lussu M, et al. Impact of Early Postnatal Nutrition on the NMR Urinary Metabolic Profile of Infant. J Proteome Res. 2016;15(10):3712-23.

99. Dessì A, Murgia A, Agostino R, et al. Exploring the Role of Different Neonatal Nutrition Regimens during the First Week of Life by Urinary GC-MS Metabolomics. Int J Mol Sci. 2016;17(2):265.

100. Shoji $H$, Shimizu T. Effect of human breast milk on biological metabolism in infants. Pediatr Int. 2019;61:6-15.

101. Chow J, Panasevich MR, Alexander D, et al. Fecal metabolomics of healthy breast-fed versus formula-fed infants before and during in vitro batch culture fermentation. J Proteome Res. 2014;13(5):2534-42.

102. Liu Z, Roy NC, Guo Y, et al. Human Breast Milk and Infant Formulas Differentially Modify the Intestinal Microbiota in Human Infants and Host Physiology in Rats. J Nutr. 2016;146:191-9. 
103. Bazanella M, Maier TV, Clavel T, et al. Randomized controlled trial on the impact of early-life intervention with bifidobacteria on the healthy infant fecal microbiota and metabolome. Am J Clin Nutr. 2017;106(5):1274-86.

104. Hewelt-Belka W, Garwolińska D, Belka M,et al. A new dilution-enrichment sample preparation strategy for expanded metabolome monitoring of human breast milk that overcomes the simultaneous presence of low- and high-abundance lipid species. Food Chem. 2019;288:154-61. 105. Koulman A, Furse S, Baumert M, et al. Rapid profiling of triglycerides in human breast milk using liquid extraction surface analysis Fourier transform mass spectrometry reveals new very long chain fatty acids and differences within individuals. Rapid Commun Mass Spectrom.

2019;33(15):1267-76.

106. George AD, Gay MCL, Trengove RD, et al. Human Milk Lipidomics: Current Techniques and Methodologies. Nutrients. 2018;10(9):E1169.

107. Hampel D, Shahab-Ferdows S, Hossain M, et al. Human Milk Metabolomics Using Biocrates AbsoluteIDQ p180 Kit Assay (OR06-04-19)Curr Dev Nutr. 2019;3(1):nzz036.

108. Minegishi N, Nishijima I, Nobukuni T' et al. Biobank Establishment and Sample Management in the Tohoku Medical Megabank Project. Tohoku J Exp Med. 2019;248(1):45-55.

109. Bertino E, Peila C, Cresi F, et al. Donor Human Milk: Effects of Storage and Heat Treatment on Oxidative Stress Markers. Front Pediatr. 2018;6:253.

110. Peila C, Coscia A, Bertino E, et al. Heme oxygenase-1 in donor human milk. Curr Pediatr Res. 2016;20(1\&2):304-8.

111. Peila C, Emmerik NE, Giribaldi M, et al. Human milk processing: a systematic review of innovative techniques to ensure the safety and quality of donor milk. J Pediatr Gastroenterol Nutr.2017;64(3):353-61.

112. Li Volti G, Galvano F, Frigiola Guccione S, et al. Potential immunoregulatory role of heme oxygenase-1 in human milk: a combined biochemical and molecular modeling approach. J Nutr Biochem. 2010;21(9):865-71.

113. Fanos V, Pintus R, Dessì A. Clinical Metabolomics in Neonatology: From Metabolites to Diseases. Neonatology. 2018;113(4):406-13. 


\begin{tabular}{|c|c|c|c|c|c|c|c|}
\hline TOPIC & $\begin{array}{l}\text { AIM OF THE } \\
\text { STUDY }\end{array}$ & POPULATION & $\begin{array}{c}\text { BM } \\
\text { SAMPLES }\end{array}$ & METHOD & RESULTS & CONCLUSIONS & $\begin{array}{c}\text { AUTOR } \\
\text { (year) [Ref] }\end{array}$ \\
\hline $\begin{array}{l}\text { Maternal } \\
\text { factors }\end{array}$ & $\begin{array}{c}\text { Evaluating } \\
\text { GDM effects } \\
\text { on colostrum } \\
\text { whey } \\
\text { proteome }\end{array}$ & $\begin{array}{l}\mathrm{N}=6 \text { GDM vs } \\
\mathrm{n}=12 \text { healthy } \\
\text { mothers }\end{array}$ & $\begin{array}{l}\text { Samples } \\
\text { collected } \\
\text { between } 1 \\
\text { and } 3 \text { days } \\
\text { of lactation }\end{array}$ & LC-MS & $\begin{array}{l}\mathrm{N}=601 \text { proteins detected; } \\
\mathrm{n}=27 \text { resulted the best } \\
\text { indicators of GDM. } \\
\mathrm{N}=10 \text { proteins } \\
\text { significantly different in } \\
\text { GDM vs healthy mothers }\end{array}$ & $\begin{array}{l}\text { GDM changes } \\
\text { colostrum } \\
\text { proteome, } \\
\text { especially proteins } \\
\text { with nutritional } \\
\text { and immunity } \\
\text { roles }\end{array}$ & $\begin{array}{c}\text { Grapov } \\
(2015) \\
{[54]}\end{array}$ \\
\hline $\begin{array}{l}\text { Maternal } \\
\text { factors }\end{array}$ & $\begin{array}{l}\text { Evaluating } \\
\text { BM } \\
\text { metabolome } \\
\text { during AKI }\end{array}$ & $\begin{array}{c}\mathrm{N}=1 \mathrm{AKI} \\
\text { mother and } \mathrm{n}=1 \\
\text { healthy control }\end{array}$ & $\begin{array}{c}\text { BM } \\
\text { samples } \\
\text { obtained on } \\
\text { day } 1 \text { and } 4 \\
\text { (before HD } \\
\text { in AKI } \\
\text { mother) } \\
\text { and on day } \\
4 \text { in healthy } \\
\text { mother }\end{array}$ & ${ }^{1} \mathrm{H}-\mathrm{NMR}$ & $\begin{array}{l}\text { AKI mother on day 4: } \\
\text { lower alanine, glutamine, } \\
\text { glutamate, glycine, } \\
\text { valine, glucose, citrate, } \\
\text { glycerol, } \\
\text { phosphocholine, } \\
\text { valerate. Similar lactose. } \\
\text { Higher maltose, } \\
\text { creatinine, hippurate, } \\
\text { creatine, creatine } \\
\text { phosphate, acetone } \\
\text { choline and pyruvate. No } \\
\text { difference in FAs. } \\
\text { Higher Ph. } \\
\text { Iodinaxol decreased } \\
\text { from day } 1 \text { to day } 4 \text { ( } 55 \\
\text { to } 28 \text { mg I/mL). } \\
\text { Dye radio contrast: not } \\
\text { significant accumulation } \\
\text { in BM }\end{array}$ & $\begin{array}{l}\text { AKI can change } \\
\text { BM composition, } \\
\text { reducing amino } \\
\text { acids and } \\
\text { increasing } \\
\text { catabolites. } \\
\text { Breastfeeding } \\
\text { seems safe also } \\
\text { after dye contrast } \\
\text { and maternal AKI }\end{array}$ & $\begin{array}{c}\text { Chruscicki } \\
\text { (2017) } \\
\text { [55] }\end{array}$ \\
\hline $\begin{array}{l}\text { Maternal } \\
\text { factors }\end{array}$ & $\begin{array}{l}\text { Comparing } \\
\text { BM in } \\
\text { healthy } \\
\text { women from } \\
5 \text { different } \\
\text { countries }\end{array}$ & $\begin{array}{c}\mathrm{N}=29 \\
\text { Australian, } \\
\mathrm{n}=12 \text { Japan, } \\
\mathrm{n}=18 \text { USA, } \\
\mathrm{n}=40 \text { Norway } \\
\text { and } \mathrm{n}=10 \text { South } \\
\text { African mothers }\end{array}$ & $\begin{array}{c}\mathrm{N}=109 \\
\text { samples } \\
\text { collected at } \\
1 \text { month } \\
\text { postpartum }\end{array}$ & ${ }^{1} \mathrm{H}-\mathrm{MRN}$ & $\begin{array}{c}\mathrm{N}=28 \text { metabolites } \\
\text { detected. } \\
\text { Three clusters of milk } \\
\text { separation: Black, } \\
\text { Caucasian and Asian. } \\
\text { Highest variation in } \\
\text { African samples. } \\
\text { In South African } \\
\text { mothers, lactose, 2- } \\
\text { oxoglutarate, citrate and } \\
\text { creatine, creatine- } \\
\text { phosphate, creatinine, } \\
\text { betaine and glycerol- } \\
\text { phosphocholine higher } \\
\text { than Norwegian (and, } \\
\text { except for 2-oxoglurate } \\
\text { and glycerol } \\
\text { phosphocholine, than } \\
\text { Australian samples). } \\
\text { Glutamine lower in } \\
\text { Norwegian vs US. In } \\
\text { Japanese women, higher } \\
\text { levels of pyruvate and } \\
\text { lactate than Norwegian. } \\
\text { Methanol lower in } \\
\text { Norway. Lactate } \\
\text { differentiated Asian } \\
\text { samples; Black } \\
\text { population: } 2- \\
\text { Oxoglutarate, creatine, } \\
\text { creatine phosphate, } \\
\text { creatinine, betaine and } \\
\text { glycerophosphocholine } \\
\text { higher and valine lower. } \\
\text { Glutamate, glutamine, } \\
\text { glucose, and } \\
\text { phosphocholine } \\
\text { characterized Caucasian } \\
\text { samples, lower in lactate } \\
\text { and fucose than Asian }\end{array}$ & $\begin{array}{l}\text { Differences in } \\
\text { milk metabolites } \\
\text { were detected } \\
\text { according to } \\
\text { geographic } \\
\text { variations. BM is } \\
\text { influenced by } \\
\text { regional maternal } \\
\text { diet, health status, } \\
\text { genetics and } \\
\text { breastfeeding } \\
\text { practices }\end{array}$ & $\begin{array}{c}\text { Gay (2018) } \\
\text { [23] }\end{array}$ \\
\hline $\begin{array}{l}\text { Maternal } \\
\text { factors } \\
\text { and } \\
\text { micro- } \\
\text { biome }\end{array}$ & $\begin{array}{l}\text { Exploring the } \\
\text { influence of } \\
\text { maternal } \\
\text { geographic } \\
\text { provenience } \\
\text { and mode of } \\
\text { delivery on } \\
\text { BM }\end{array}$ & $\begin{array}{c}\mathrm{N}=79 \text { lactating } \\
\text { mothers from } \\
\text { Finland }(\mathrm{n}=20), \\
\text { Spain }(\mathrm{n}=20), \\
\text { South Africa } \\
(\mathrm{n}=19) \text {, and } \\
\text { China }(\mathrm{n}=20) . \\
\text { Vaginal }\end{array}$ & $\begin{array}{c}\text { BM } \\
\text { samples at } \\
1 \text { month of } \\
\text { lactation }\end{array}$ & ${ }^{1} \mathrm{H}-\mathrm{NMR}$ & $\begin{array}{c}\mathrm{N}=68 \text { metabolites in } \\
\mathrm{MM} \text { ( } \mathrm{n}=23 \text { amino acids, } \\
\mathrm{n}=18 \text { sugars, } \mathrm{n}=10 \text { lipids } \\
\text { and FAs, } \mathrm{n}=7 \text { energy } \\
\text { metabolites, vitamins or } \\
\text { nucleic acids, microbial } \\
\text { metabolites or additives). } \\
\text { Variating levels of }\end{array}$ & $\begin{array}{c}\text { BM metabolome } \\
\text { highly correlated } \\
\text { to geographical } \\
\text { variations and } \\
\text { delivery mode. } \\
\text { BM metabolome } \\
\text { highly influences } \\
\text { microbial } \\
\end{array}$ & $\begin{array}{c}\text { Gómez- } \\
\text { Gallego } \\
(2018) \\
{[25]}\end{array}$ \\
\hline
\end{tabular}




\begin{tabular}{|c|c|c|c|c|c|c|c|}
\hline & $\begin{array}{l}\text { composition } \\
\text { and } \\
\text { microbiome }\end{array}$ & $\begin{array}{c}\text { delivery }(\mathrm{n}=10 \\
\text { for each } \\
\text { country); } \\
\text { caesarean } \\
\text { section }(\mathrm{n}=10 \\
\text { China, Finland } \\
\text { and Spain; } \mathrm{n}=9 \\
\text { South Africa) }\end{array}$ & & & $\begin{array}{c}\text { galactose, LNFP III, } \\
\text { LNFP I and 2'FL, 3'FL, } \\
\text { LNDFH II, 2- } \\
\text { hydroxybutyrate, 3- } \\
\text { hydroxybutyrate, } \\
\text { proline, N-acetyl lysine, } \\
\text { methyl-histidine, } \\
\text { dimethylamine, } \\
\text { kynurenine, urea, } \\
\text { creatine, creatine } \\
\text { phosphate, } \\
\text { formate, lactate, acetate, } \\
\text { phosphocholine, } \\
\text { acetylcholine, LDL, } \\
\text { VLDL, ethanolamine, } \\
\text { riboflavin, hippurate, } \\
\text { spermidine, spermine } \\
\text { and uridine. Chinese } \\
\text { mothers: higher 3'FL, } \\
\text { LNFP III than Finland. } \\
\text { Finland: higher LNFP I. } \\
\text { Spain: higher 2'FL, } \\
\text { SCFA, acetate and } \\
\text { formate. South Africa: } \\
\text { higher 3'FL. LDL and } \\
\text { VLDL higher in Spain } \\
\text { and Finland. In vaginal } \\
\text { delivery: higher 3- } \\
\text { hydroxybutyrate and } \\
\text { LNFP III and lower } \\
\text { butyrate, ethanolamine, } \\
\text { proline and urea }\end{array}$ & communities & \\
\hline $\begin{array}{l}\text { Maternal } \\
\text { secretor } \\
\text { status }\end{array}$ & $\begin{array}{l}\text { Analyzing } \\
\text { HMOs } \\
\text { content in } \\
\text { BM }\end{array}$ & $\begin{array}{c}\mathrm{N}=58 \text { mothers } \\
\text { of full-term } \\
\text { neonates }(\mathrm{n}=48 \\
\text { AGA } \mathrm{n}=2 \mathrm{LGA}, \\
\mathrm{n}=10 \text { SGA) }\end{array}$ & $\begin{array}{l}\mathrm{n}=58 \mathrm{BM} \\
\text { samples of } \\
\text { colostrum } \\
\text { (on the } 4^{\text {th }} \\
\text { day of } \\
\text { lactation) }\end{array}$ & ${ }^{1} \mathrm{H}-\mathrm{NMR}$ & $\begin{array}{c}\text { Se-: more } \alpha 1,3 / 4 \text {-linked } \\
\text { fucosyl- } \\
\text { oligosaccharides, with } \\
\text { fucose linked only by } \\
\alpha 1,3 \text { or } \alpha 1,4 \text { glycosidic } \\
\text { bonds (while } \alpha 1,2 \\
\text { fucosyloligosaccharides } \\
\text { were lacking); Se+ } \\
\text { group: } \alpha 1,2 \\
\text { fucosyloligosaccharide } \\
\text { units abundant. Not } \\
\text { significant differences } \\
\text { according to GA, BW, } \\
\text { delivery mode and } \\
\text { gender }\end{array}$ & $\begin{array}{l}\text { A clear separation } \\
\text { occurred between } \\
\mathrm{Se} \text { - and } \mathrm{Se}+ \\
\text { groups }\end{array}$ & $\begin{array}{c}\text { Dessì } \\
(2018) \\
{[57]}\end{array}$ \\
\hline Multiples & $\begin{array}{l}\text { Investigating } \\
\text { BM } \\
\text { composition } \\
\text { in multiple } \\
\text { pregnancies }\end{array}$ & $\begin{array}{c}\mathrm{N}=51 \text { multiples } \\
(\mathrm{n}=19 \text { twins, } \\
\mathrm{n}=5 \text { triplets. GA } \\
<33 \mathrm{w} \text { and } \mathrm{BW} \\
\quad<1500 \mathrm{~g}) . \\
\mathrm{N}=28 \text { singletons } \\
(\mathrm{GA} \leq 28 \mathrm{w})\end{array}$ & $\begin{array}{c}\mathrm{N}=103 \\
\text { samples } \\
\text { collected } \\
\text { between the } \\
1^{\text {st }} \text { and the } \\
20^{\text {th }} \mathrm{w} \text { of } \\
\text { life }\end{array}$ & $\begin{array}{c}\text { mid- } \\
\text { infrared } \\
\text { analyzer } \\
\text { (MilkoScan } \\
\text { FT2) }\end{array}$ & Proteins and lactose & $\begin{array}{c}\text { Proteins } \\
\text { significantly } \\
\text { higher in } \\
\text { multiples, mostly } \\
\text { influenced by GA } \\
\text { (decreasing over } \\
\text { lactation). Lactose } \\
\text { content higher in } \\
\text { singletons }\end{array}$ & $\begin{array}{c}\text { Congiu } \\
(2019) \\
{[67]}\end{array}$ \\
\hline $\begin{array}{c}\text { BM vs } \\
\text { FM }\end{array}$ & $\begin{array}{l}\text { Comparing } \\
\text { BM } \\
\text { composition } \\
\text { to eight } \\
\text { different } \\
\text { kinds of FM }\end{array}$ & $\begin{array}{l}\text { Mothers } \\
\text { delivering full- } \\
\text { term }\end{array}$ & $\begin{array}{c}\mathrm{N}=31 \mathrm{BM} \\
\text { samples } \\
\text { between 3- } \\
26 \mathrm{w} \text { of } \\
\text { lactation. } \\
\mathrm{N}=31 \\
\text { samples of } \\
\text { eight } \\
\text { different } \\
\text { kinds of } \\
\text { FM }\end{array}$ & GC-MS & $\begin{array}{c}\text { Orotic acid and } \\
\text { isomaltulose (189.8 } \\
\mathrm{mg} / \mathrm{dL} \text { ) only in FM. FM: } \\
\text { higher malic acid, } \\
\text { glucose } 122.8 \mathrm{mg} / \mathrm{dL}, \\
\text { fructose, galactose, } \\
\text { mannitol } 27.6 \mathrm{mg} / \mathrm{dL} \text {. } \\
\text { BM: higher amino acids } \\
\text { (threonine, valine, } \\
\text { alanine, serine, glutamic } \\
\text { acid } 82.7 \mathrm{mg} / \mathrm{dL} \text {, glycine } \\
\text { and pyroglutamic acid } \\
47.9 \mathrm{mg} / \mathrm{dL}), \text { urea, } \\
\text { inositols (myo-inositol } \\
46.1 \mathrm{mg} / \mathrm{dL} \text { and } \\
\text { scylloinositol) }\end{array}$ & $\begin{array}{l}\text { Metabolome } \\
\text { highly different in } \\
\text { FM and BM and } \\
\text { varies according } \\
\text { to the kind of } \\
\text { analyzed formula }\end{array}$ & $\begin{array}{c}\text { Scano } \\
(2016) \\
{[76]}\end{array}$ \\
\hline $\begin{array}{c}\text { BM vs } \\
\text { FM }\end{array}$ & $\begin{array}{l}\text { Evaluation of } \\
\text { BM and FM } \\
\text { lipids. } \\
\text { Vegetables, } \\
\quad \text { fish, }\end{array}$ & $\begin{array}{l}\text { Different } \\
\text { mothers }\end{array}$ & $\begin{array}{l}\mathrm{N}=10 \mathrm{BM} \\
\text { samples, } \\
\mathrm{N}=12 \mathrm{FM} \\
\text { samples }\end{array}$ & ${ }^{1} \mathrm{H}-\mathrm{NMR}$ & $\begin{array}{c}\text { FM: lower SFAs, higher } \\
\text { UFAs }(38.20 \% \text { vs } \\
30.59 \%) \text { and } \\
\text { comparable PUFAs } \\
(9.92 \% \text { vs } 17.96 \%) .\end{array}$ & $\begin{array}{l}\text { BM and FM show } \\
\text { similar lipid } \\
\text { profiles. } \\
\text { Significant } \\
\text { difference in the }\end{array}$ & $\begin{array}{c}\text { Lopes } \\
(2018) \\
{[77]}\end{array}$ \\
\hline
\end{tabular}




\begin{tabular}{|c|c|c|c|c|c|c|c|}
\hline & $\begin{array}{l}\text { microalgae } \\
\text { oil and raw } \\
\text { materials } \\
\text { measured in } \\
\text { FM }\end{array}$ & & & & $\begin{array}{l}\text { SFAs esterified mainly } \\
\text { in the sn- } 1,3 \text { position } \\
(33.07 \text { vs } 4.93 \%) \text { and } \\
\text { PUFAs in the sn-2 } \\
\text { position }(9.57 \% \text { vs } \\
7.05 \%) \text { than BM. BM: } \\
\text { higher of SFAs in the sn- } \\
2 \text { position }(26.03 \% \text { vs } \\
2.93 \%) \text { and PUFAs in } \\
\text { the sn-1,3 position } \\
(15.35 \% \text { vs } 3.94 \%)\end{array}$ & $\begin{array}{l}\text { stereospecific FAs } \\
\text { distribution }\end{array}$ & \\
\hline $\begin{array}{l}\text { BM VS } \\
\text { FM and } \\
\text { bovine } \\
\text { milk }\end{array}$ & $\begin{array}{l}\text { Comparing } \\
\text { BM, FM and } \\
\text { bovine milk } \\
\text { metabolome }\end{array}$ & $\begin{array}{c}\mathrm{N}=30 \text { lactating } \\
\text { mothers }\end{array}$ & $\begin{array}{l}\mathrm{N}=30 \mathrm{BM} \\
\text { samples } \\
\mathrm{N}=20 \\
\text { bovine } \\
\text { samples } \\
\mathrm{N}=20 \mathrm{FM}\end{array}$ & $\begin{array}{c}\text { GC- } \\
\text { TOFMS } \\
\text { and UPLC- } \\
\text { QTOFMS }\end{array}$ & $\begin{array}{l}\text { BM, FM and bovine } \\
\text { samples were clearly } \\
\text { distinct. BM: higher non- } \\
\text { esterified SFAs with } \\
\text { aliphatic tails }<16 \\
\text { carbons, MUFAs, } \\
\text { PUFAs, myristoleic } \\
\text { (14C:1), palmitoleic } \\
\text { (16C:1), oleic (C18:1) } \\
\text { eicosenoic (C20:1), } \\
\text { linoleic (C18:2), alpha- } \\
\text { linolenic (C18:3), } \\
\text { eicosapentaenoic } \\
\text { (C20:5), } \\
\text { docosapentaenoic } \\
\text { (C22:5), } \\
\text { docosahexaenoic } \\
\text { (C22:6), gamma- } \\
\text { linolenic (C18:3), } \\
\text { eicosadienoic (C20:2), } \\
\text { eicosatrienoic (C20:3), } \\
\text { arachidonic (C20:4) and } \\
\text { docosadienoic (C22:2) } \\
\text { acids, 5-oxoproline, } \\
\text { alanine, arginine, } \\
\text { glutamic acid, glutamine, } \\
\text { glycine, serine, taurine, } \\
\text { tyrosine, valine and } \\
\text { fucose. Lower TCA } \\
\text { intermediates, 2- } \\
\text { ketoglutaric, 2- } \\
\text { ketoglutaramic, citric, } \\
\text { fumaric, 2- } \\
\text { ketoglutaramic, cis- } \\
\text { aconitic, malic, palmitic } \\
\text { and stearic acids, } \\
\text { phenylalanine, histidine, } \\
\text { taurine, proline, } \\
\text { arabinose, mannose, } \\
\text { glucosamine, } \\
\text { acetylglucosamine, } \\
\text { fructose, maltose and } \\
\text { threitol. } \\
\text { Mostly varying } \\
\text { metabolites: NEFAs, } \\
\text { FAAs, TCA, free } \\
\text { carbohydrates }\end{array}$ & $\begin{array}{l}\text { BM, FM and } \\
\text { bovine milk have } \\
\text { their peculiar } \\
\text { metabolic profile, } \\
\text { unique for each } \\
\text { milk type }\end{array}$ & $\begin{array}{c}\text { Quian } \\
\text { (2016) } \\
{[78]}\end{array}$ \\
\hline $\begin{array}{c}\text { BM } \\
\text { analysis }\end{array}$ & $\begin{array}{l}\text { Evaluating } \\
\text { BM samples } \\
\text { with a } \\
\text { combined } \\
\text { multiplatform } \\
\text { approach }\end{array}$ & $\begin{array}{c}\mathrm{N}=57 \text { full-term } \\
\text { delivering } \\
\text { mothers }\end{array}$ & $\begin{array}{c}\mathrm{N}=70 \\
\text { samples } \\
\text { collected } \\
\text { between 2- } \\
80 \text { days of } \\
\text { lactation } \\
\text { and } \\
\text { compared } \\
\text { in 3 } \\
\text { intervals: } \\
1-5 \mathrm{~d}, 6-10 \\
\mathrm{~d},>10 \mathrm{~d}\end{array}$ & $\begin{array}{l}\text { HPLC-MS, } \\
\text { LC-MS, } \\
\text { GC-MS, } \\
\text { CE-MS, } \\
{ }^{1} \text { H-NMR }\end{array}$ & $\begin{array}{l}\mathrm{N}=710 \text { metabolites } \\
\text { identified. Lactose, } \\
\text { fucose, di- and } \\
\text { triacylglycerols, } \\
\text { aminoacids and short } \\
\text { and medium chain FAs } \\
\text { increased during } \\
\text { lactation. } \\
\text { Several HMOs, } \\
\text { phosphocholines citrate } \\
\text { and pyruvate decreased }\end{array}$ & $\begin{array}{l}\text { BM maturation } \\
\text { seems to depend } \\
\text { on neonatal needs } \\
\text { during lactation }\end{array}$ & $\begin{array}{c}\text { Andreas } \\
(2015) \\
{[63]}\end{array}$ \\
\hline $\begin{array}{c}\text { BM } \\
\text { analysis }\end{array}$ & $\begin{array}{l}\text { Evaluating } \\
\text { BM } \\
\text { composition } \\
\text { during the } \\
\text { first month of } \\
\text { lactation in } \\
\text { full-term and }\end{array}$ & $\begin{array}{c}\mathrm{N}=28 \text { mothers. } \\
\mathrm{N}=15 \text { full-term } \\
(>37 \mathrm{w}) \text { and } \mathrm{n}= \\
13 \text { preterm }(< \\
37 \mathrm{w}) \text { delivering }\end{array}$ & $\begin{array}{l}\text { Samples of } \\
\text { colostrum } \\
\text { (day } 0-5 \text { of } \\
\text { lactation), } \\
\text { TM (day } \\
14 \text { ) and } \\
\text { MM (day }\end{array}$ & ${ }^{1} \mathrm{H}-\mathrm{NMR}$ & $\begin{array}{c}\mathrm{N}=69 \text { metabolites } \\
\text { detected: } \mathrm{n}=15 \text { sugars, } \\
\mathrm{n}=23 \text { amino acids, } \mathrm{n}=11 \\
\text { energy-related } \\
\text { metabolites, } \mathrm{n}=10 \mathrm{FAs} \\
\mathrm{n}=3 \text { nucleotides, } \mathrm{n}=2 \\
\text { vitamins, and } \mathrm{n}=5\end{array}$ & $\begin{array}{l}\text { BM metabolites } \\
\text { vary during the } \\
\text { first month of } \\
\text { lactation. The } \\
\text { highest variability } \\
\text { shown in pre-term } \\
\text { samples }\end{array}$ & $\begin{array}{c}\text { Spevacek } \\
(2015) \\
{[20]}\end{array}$ \\
\hline
\end{tabular}




\begin{tabular}{|c|c|c|c|c|c|c|c|}
\hline & $\begin{array}{l}\text { pre-term } \\
\text { samples }\end{array}$ & & 28) & & $\begin{array}{l}\text { bacterial metabolites. } \\
\text { Colostrum and MM } \\
\text { showed a different } \\
\text { clusterization. Some } \\
\text { metabolites increased } \\
\text { during lactation. } \\
\text { Most HMOs decreased. } \\
\text { Full-term colostrum: } \\
\text { higher total and neutral } \\
\text { HMOs, 2'-FL, 3'-GSL, } \\
\text { 3'-SL, 6'-SL, fucose, } \\
\text { LNFP III, LnNT } \\
\text { acetylcarnitine, betaine, } \\
\text { isoleucine, lysine, } \\
\text { taurine, choline, myo- } \\
\text { Inositol, hypoxanthine, } \\
\text { 2-Oxoglutarate, creatine, } \\
\text { fumarate, lactate, } \\
\text { pyruvate, hyppurate and } \\
\text { methanol. Pre-term MM: } \\
\text { higher LNFPII, lactose, } \\
\text { alanine, azelate, } \\
\text { butyrate, caprylate, } \\
\text { Glycero-3- } \\
\text { phosphocholine, 2- } \\
\text { oxoglutarate, acetone, } \\
\text { lactate, pyruvate, } \\
\text { acetoin. Full-term MM: } \\
\text { higher 3' FL, glucose, } \\
\text { lactose, 2- } \\
\text { Aminobutyrate, alanine, } \\
\text { carnitine, glutamate, } \\
\text { glutamine, histidine, } \\
\text { urea, valine, butyrate, } \\
\text { azelate, caprate, } \\
\text { caprylate, ethanolamine, } \\
\text { glycero-3- } \\
\text { phosphocholine, acetone, } \\
\text { creatine phosphate, } \\
\text { AMP, creatinine, } \\
\text { dimethyl sulfone. N=10 } \\
\text { full-term delivering and } \\
\text { n=10 preterm delivering } \\
\text { mothers resulted Se+ }\end{array}$ & & \\
\hline $\begin{array}{c}\text { BM } \\
\text { analysis }\end{array}$ & $\begin{array}{l}\text { First study } \\
\text { investigating } \\
\text { metabolic } \\
\text { profiles of } \\
\text { BM samples } \\
\text { from pre-term } \\
\text { and full-term } \\
\text { delivering } \\
\text { mothers, } \\
\text { according to } \\
\text { GA at } \\
\text { delivery and } \\
\text { lactation } \\
\text { phase }\end{array}$ & $\begin{array}{l}\mathrm{N}=45 \text { mothers, } \\
\mathrm{n}=30 \text { delivering } \\
\text { full-term and } \\
\mathrm{n}=15 \text { delivering } \\
\text { pre-term }(<37 \\
\mathrm{w})\end{array}$ & $\begin{array}{c}\mathrm{N}=92 \\
\text { samples. } \\
\mathrm{N}=5 \\
\text { colostrum } \\
(<5 \text { days } \\
\text { post- } \\
\text { partum }) \\
\mathrm{N}=4 \mathrm{TM}(6 \\
\text { days- } 2 \mathrm{w} \\
\text { post- } \\
\text { partum }) \\
\mathrm{N}=21 \\
\mathrm{MM}(>2 \\
\mathrm{w})\end{array}$ & ${ }^{1} \mathrm{H}-\mathrm{NMR}$ & $\begin{array}{c}\text { Metabolic differences in } \\
\text { colostrum, TM and MM. } \\
\text { Full-term colostrum: } \\
\text { higher valine, leucine, } \\
\text { betaine, and creatinine } \\
\text { instead MM. } \\
\text { Full-term MM: higher } \\
\text { glutamate, caprylate and } \\
\text { caprate than colostrum. } \\
\text { Pre-term colostrum: } \\
\text { higher HMOs, citrate } \\
\text { and creatinine. } \\
\text { MM: Higher caprylate, } \\
\text { caprate, valine, leucine, } \\
\text { butyrate, alanine, } \\
\text { glutamate, pantothenate } \\
\text { 3-FL, LNDFH I and } \\
\text { lactic acid. Colostrum: } \\
\text { higher fucosylated } \\
\text { HMOs, fucose, N- } \\
\text { acetylneuraminic acid, } \\
\text { N-acetylglucosamine, } \\
\text { valine, leucine, } \\
\text { pantothenate, citric acid, } \\
\text { lactic acid, choline, } \\
\text { betaine ,creatinine } \\
\text { fucosyl moieties, N- } \\
\text { acetylneuraminic acid, } \\
\text { N-acetylglucosamine, } \\
\text { 3'SL, 6'SL and 2'FL. } \\
\text { Most discriminating } \\
\text { metabolites between full- }\end{array}$ & $\begin{array}{l}\text { BM for pre-term } \\
\text { newborns is } \\
\text { significantly } \\
\text { different from } \\
\text { full-term } \\
\text { (depending on } \\
\text { GA). BM } \\
\text { metabolome } \\
\text { varies across } \\
\text { lactation. Changes } \\
\text { determine a } \\
\text { realignment of } \\
\text { pre-term samples } \\
\text { to full-term after } \\
5-7 \mathrm{w}, \\
\text { independently } \\
\text { from GA at birth }\end{array}$ & $\begin{array}{c}\text { Sundekilde } \\
\text { (2016) } \\
\text { [62] }\end{array}$ \\
\hline
\end{tabular}




\begin{tabular}{|c|c|c|c|c|c|c|c|}
\hline & & & & & $\begin{array}{c}\text { term and pre-term BM } \\
\text { samples were carnitine, } \\
\text { caprylate, caprate, } \\
\text { pantothenate, urea, } \\
\text { lactose, } \\
\text { oligosaccharides, citrate, } \\
\text { phosphocholine, choline } \\
\text { and formate. } \\
\text { Pre-term: Higher Citrate, } \\
\text { lactose, phosphocholine, } \\
\text { fucosyl moieties, N- } \\
\text { acetylneuraminic acid, } \\
\text { N-acetylglucosamine, } \\
\text { 3'SL, 6'SL, LNDFH I, } \\
\text { glutamate, citric acid, } \\
\text { phosphocholine, choline } \\
\text { and formic acid. Full- } \\
\text { term: higher carnitine, } \\
\text { caprylate, caprate, } \\
\text { pantothenate, beta- } \\
\text { hydroxybutyrate, urea }\end{array}$ & & \\
\hline $\begin{array}{c}\text { BM } \\
\text { analysis }\end{array}$ & $\begin{array}{c}\text { Investigating } \\
\text { metabolomics } \\
\text { changes over } \\
\text { lactation on a } \\
\text { single-patient } \\
\text { study }\end{array}$ & $\mathrm{N}=1$ mother & $\begin{array}{l}\mathrm{N}=15 \mathrm{BM} \\
\text { samples } \\
\text { collected } \\
\text { twice a day } \\
\text { on the days } \\
9,12,24, \\
31,60,85, \\
86 \text { and } 87 \\
\text { of lactation }\end{array}$ & ${ }^{1} \mathrm{H}-\mathrm{NMR}$ & $\begin{array}{c}\text { Late stage characterized } \\
\text { by an increase in lactose, } \\
\text { choline, alanine, } \\
\text { glutamate, glutamine, } \\
\text { butyrate and formate } \\
\text { levels and a reduction in } \\
\text { citrate, phosphocholine, } \\
\text { glycerophosphocholine } \\
\text { and N- } \\
\text { acetylglucosamine }\end{array}$ & $\begin{array}{c}\text { Separation } \\
\text { between the } \\
\text { samples collected } \\
\text { in the early } \\
\text { lactation (9-24 } \\
\text { days) and late } \\
\text { lactation (31-87 } \\
\text { days) }\end{array}$ & $\begin{array}{c}\mathrm{Wu}(2016) \\
{[60]}\end{array}$ \\
\hline $\begin{array}{c}\text { BM } \\
\text { analysis }\end{array}$ & $\begin{array}{c}\text { Metabolic } \\
\text { comparison } \\
\text { between BM } \\
\text { and bovine } \\
\text { milk }\end{array}$ & $\begin{array}{c}\mathrm{N}=30 \text { Chinese } \\
\text { mothers } \\
\text { between } 7-14 \mathrm{~d} \\
\text { of lactation }\end{array}$ & $\begin{array}{c}\mathrm{N}=30 \mathrm{BM} \\
\text { samples } \\
\mathrm{N}=30 \\
\text { bovine } \\
\text { samples }\end{array}$ & $\begin{array}{l}\text { iTRAQ } \\
\text { combined } \\
\text { with LC- } \\
\text { MS }\end{array}$ & $\begin{array}{c}\text { BM and bovine samples } \\
\text { underwent a clear } \\
\text { separation. Total free } \\
\text { amino acids: } 0.32 \mathrm{~g} / \mathrm{L} \text { in } \\
\text { bovine milk and } 0.63 \mathrm{~g} / \mathrm{L} \\
\text { in BM. Total hydrolytic } \\
\text { amino acids of } 4.2 \mathrm{~g} / \mathrm{L} \\
\text { and } 2.2 \mathrm{~g} / \mathrm{L} \text { respectively. } \\
\mathrm{N}=42 \text { amino acids } \\
\text { detected: } \mathrm{n}=27 \text { higher in } \\
\text { BM than bovine } \\
\text { samples. } \\
\text { BM: higher histidine, } \\
\text { leucine, lysine, } \\
\text { phenylalanine, citrulline, } \\
\text { 1-Methyl-L-histidine, } \\
\text { glutamic acid, glutamine, } \\
\text { threonine, serine, } \\
\text { glycine. Asparagine, } \\
\text { aspartic acid and } \\
\text { cysteine exclusively in } \\
\text { BM. Bovine samples: } \\
\text { higher isoleucine, } \\
\text { leucine, valine, histidine, } \\
\text { methionine, threonine, } \\
\text { arginine, tyrosine, } \gamma- \\
\text { aminobutyric acid, } \\
\text { taurine, } \alpha \text {-aminobutyric } \\
\text { acid, phenylalanine, } \\
\text { ethanolamine and } \\
\text { glycine }\end{array}$ & $\begin{array}{l}\text { Metabolomics } \\
\text { highly promising } \\
\text { to detect } \\
\text { differences in } \\
\text { amino acids } \\
\text { content in BM, } \\
\text { bovine samples } \\
\text { and FM }\end{array}$ & $\begin{array}{c}\text { Liang } \\
(2018) \\
{[79]}\end{array}$ \\
\hline $\begin{array}{c}\text { BM } \\
\text { analysis }\end{array}$ & $\begin{array}{c}\text { Evaluating } \\
\text { BM } \\
\text { differences } \\
\text { between full- } \\
\text { term and pre- } \\
\text { term samples } \\
\text { during } \\
\text { lactation }\end{array}$ & $\begin{array}{l}\mathrm{N}=18 \text { mothers } \\
(\mathrm{n}=12 \text { delivered } \\
\text { full-term, } \mathrm{n}=6 \\
\text { delivered pre- } \\
\text { term } 29-31 \mathrm{w} \text { of } \\
\text { GA })\end{array}$ & $\begin{array}{c}\mathrm{N}=30 \\
\text { samples - } \\
\text { full term: } \\
\mathrm{n}=12 \\
\text { collected at } \\
4-7 \text { days of } \\
\text { lactation } \\
\text {-pre-term: } \\
\mathrm{n}=3 \\
\text { samples } \\
\text { from each } \\
\text { mother, } 1-3 \\
\text { w of } \\
\text { lactation }\end{array}$ & ${ }^{1} \mathrm{H}-\mathrm{NMR}$ & $\begin{array}{l}\text { The two categories } \\
\text { characterized by two } \\
\text { different metabolic } \\
\text { profiles. } \\
\text { Pre-term samples: } \\
\text { higher lactose (4.46 } \\
\text { ppm) and HMOs, } \\
\text { especially fucosylated, } \\
\text { such as fucose (1.23 } \\
\text { ppm), N-acetyl- } \\
\text { neuraminic acid (2.06 } \\
\text { ppm) and N-acetyl- } \\
\text { glucosamine (2.04 ppm) }\end{array}$ & $\begin{array}{l}\text { BM metabolome } \\
\text { varies during } \\
\text { lactation. Pre-term } \\
\text { samples at } 3 \mathrm{w} \text { of } \\
\text { post-natal age are } \\
\text { not equal to full- } \\
\text { term }\end{array}$ & $\begin{array}{c}\text { Perrone } \\
(2018) \\
{[59]}\end{array}$ \\
\hline $\mathrm{BM}$ & Evaluating & $\mathrm{N}=30$ mothers & Samples & HPLC- & $\mathrm{N}=84$ metabolites & Samples & $\mathrm{Li}(2018)$ \\
\hline
\end{tabular}




\begin{tabular}{|c|c|c|c|c|c|c|}
\hline analysis & $\begin{array}{c}\text { changes in } \\
\text { BM } \\
\text { metabolome } \\
\text { across } \\
\text { lactation } \\
\text { stages and } \\
\text { according to } \\
\text { maternal diet } \\
\text { in a cohort of } \\
\text { Chinese } \\
\text { women }\end{array}$ & 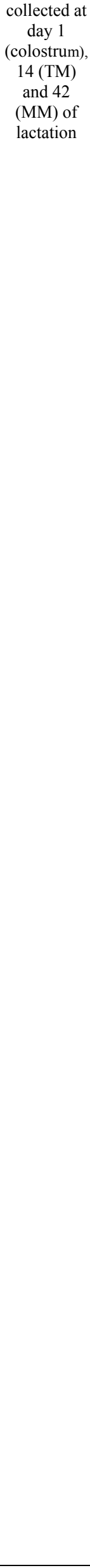 & QTOFMS & 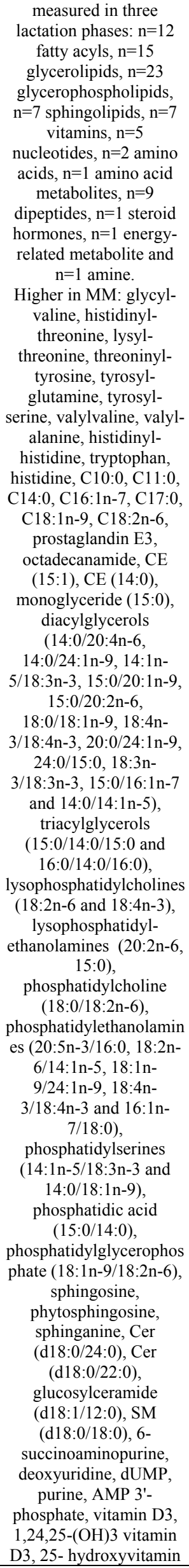 & $\begin{array}{l}\text { belonging to three } \\
\text { lactation stages } \\
\text { were clearly } \\
\text { different. } \\
\text { Metabolites' } \\
\text { variations did not } \\
\text { depend on } \\
\text { maternal dietary } \\
\text { intake }\end{array}$ & {$[61]$} \\
\hline
\end{tabular}




\begin{tabular}{|c|c|c|c|c|c|c|c|}
\hline & & & & & $\begin{array}{c}\text { D2-25-glucuronide, } \\
\text { vitamin D2, biotin, } 11 \beta \text { - } \\
\text { hydroxyprogesterone, } \\
\text { cis-Aconitic acid and } \\
\text { spermidine. } \\
\text { Colostrum: higher } \\
\text { C14:1n-5, } \\
\text { lysophosphatidylcholines } \\
\text { (22:6n-3, 16:0 and } \\
\text { 22:5n-3), } \\
\text { lysophosphatidyl- } \\
\text { ethanolamines (20:4n-6, } \\
\text { 20:3n-6 and } 22: 0), \\
\text { phosphatidylethanolamin } \\
\text { es (14:0/14:1n-5 and } \\
\text { 15:0/14:1n-5), } \\
\text { phosphatidic acid } \\
(14: 1 n-5 / 22: 6 n-3), \\
\text { retinoyl } \beta \text { - Glucuronide } \\
\text { and } \gamma \text {-tocopherol }\end{array}$ & & \\
\hline $\begin{array}{c}\text { BM } \\
\text { analysis }\end{array}$ & $\begin{array}{l}\text { Evaluating } \\
\text { the effects of } \\
\text { BM } \\
\text { composition } \\
\text { on infant } \\
\text { serum lipids } \\
\text { and amino } \\
\text { acids }\end{array}$ & $\begin{array}{c}\mathrm{N}=196 \text { dyads of } \\
\text { mothers and } \\
\text { newborns }\end{array}$ & $\begin{array}{c}\text { BM } \\
\text { collected at } \\
1 \text { and } 4 \\
\text { months of } \\
\text { lactation }\end{array}$ & GC-MS & $\begin{array}{c}\text { BM analyzed for } \\
\text { macronutrients and FAs. } \\
\text { Serum phospholipids, } \\
\text { acylcarnitines, and } \\
\text { amino acids LPC } \\
\text { correlates with BM FAs } \\
\text { and protein content, } \\
\text { especially LPC 14:0 }\end{array}$ & $\begin{array}{l}\text { LPC 14:0 } \\
\text { (associated to } \\
\text { growth } \\
\text { improvement and } \\
\text { obesity increase) } \\
\text { reflects BM } \\
\text { protein content }\end{array}$ & $\begin{array}{l}\text { Hellmuth } \\
(2018) \\
{[66]}\end{array}$ \\
\hline $\begin{array}{c}\text { BM } \\
\text { analysis }\end{array}$ & $\begin{array}{l}\text { Investigating } \\
\text { FAs BM } \\
\text { levels in } \\
\text { relation to } \\
\text { maternal } \\
\text { intake }\end{array}$ & $\begin{array}{c}\mathrm{N}=32 \text { women } \\
\text { during the first } \\
\text { month of } \\
\text { lactation }\end{array}$ & $\begin{array}{c}\mathrm{N}=32 \\
\text { samples }\end{array}$ & GC-MS & $\begin{array}{c}\text { Current dietary intake of } \\
\text { omega-3 Fas was not } \\
\text { significantly correlated } \\
\text { with BM content, while } \\
\text { their habitual intake } \\
\text { could influence BM } \\
\text { levels }\end{array}$ & $\begin{array}{l}\text { Nutritional habits } \\
\text { in the three } \\
\text { months prior } \\
\text { delivery can affect } \\
\text { BM }\end{array}$ & $\begin{array}{c}\text { Bzikowska- } \\
\text { Jura (2019) } \\
{[64]}\end{array}$ \\
\hline $\begin{array}{l}\text { Pro- } \\
\text { resolution } \\
\text { activity }\end{array}$ & $\begin{array}{l}\text { Investigating } \\
\text { BM } \\
\text { proresolution } \\
\text { antinflammat } \\
\text { ory mediators } \\
\text { in healthy } \\
\text { mothers vs } \\
\text { mastitis }\end{array}$ & $\begin{array}{c}\mathrm{N}=4 \text { healthy } \\
\text { donors. } \\
\text { Matched } \\
\text { mastitis donors }\end{array}$ & $\begin{array}{l}\text { Healthy } \\
\text { donors: } 4-8 \\
\text { w } \\
\text { postpartum. } \\
\text { Mothers } \\
\text { affected by } \\
\text { mastitis: } 1- \\
6 \text { months }\end{array}$ & LC-MS & $\begin{array}{c}\text { In BM: } \mathrm{N}=20 \text { bioactive } \\
\text { compounds belonging } \\
\text { LOX and COX } \\
\text { pathways, such as } \\
\text { resolvins, protectins, } \\
\text { maresins, lipoxins and } \\
\text { prostanoids } \\
\text { In mastitis: higher } \\
\text { proinflammatory } \\
\text { mediators (LTB4 and } \\
\text { prostanoids), lower SPM }\end{array}$ & $\begin{array}{l}\text { BM contains SPM } \\
\text { at biologically } \\
\text { relevant } \\
\text { concentration, that } \\
\text { is reduced in } \\
\text { mastitis }\end{array}$ & $\begin{array}{c}\text { Arnardottir } \\
(2016) \\
{[71]}\end{array}$ \\
\hline $\begin{array}{l}\text { Endo- } \\
\text { genous } \\
\text { mediators }\end{array}$ & $\begin{array}{l}\text { Evaluating } \\
\text { the presence } \\
\text { of endo- } \\
\text { cannabinoids } \\
\text { in BM }\end{array}$ & $\begin{array}{c}\mathrm{N}=24 \text { lactating } \\
\text { mothers }\end{array}$ & $\begin{array}{l}\text { Maternal } \\
\text { age } 18-40 \\
\text { years at } \\
\text { delivery; } \\
\text { full term } \\
\text { delivery }> \\
37 \text { w GA }\end{array}$ & LC-MS & $\begin{array}{c}\text { Variable } \\
\text { arachidonoylethanolamin } \\
\text { e, } \\
\text { palmitoylethanolamine, } \\
\text { oleoylethanolamine, } \\
\text { docosahexaenoylethanol } \\
\text { amine, } \\
\text { eicoapentaenoylethanola } \\
\text { mine, } \\
\text { eicosenoylethanolamine, } \\
\text { arachidonoylglycerol, } \\
\text { palmitoyglycerol, } \\
\text { oleoylglycerol, } \\
\text { docosahexaenoyl- } \\
\text { glycerol, } \\
\text { eicosapentaenoyl- } \\
\text { glycerol, } \\
\text { eiconenooylglycerol, } \\
\text { arachidonic acid, } \\
\text { docosahexaenoic acid, } \\
\text { and eicosapentaenoic } \\
\text { acid. DHEA higher in } \\
\text { TM }\end{array}$ & $\begin{array}{l}\text { Arachidonoyl- } \\
\text { glycerol seem } \\
\text { modulate the type } \\
1 \text { cannabinoid } \\
\text { receptor in } \\
\text { neonatal brain; } \\
\text { bioactive } \\
\text { constituents may } \\
\text { influence infant } \\
\text { health }\end{array}$ & $\begin{array}{c}\text { Gaitán } \\
\text { (2018) } \\
\text { [24] }\end{array}$ \\
\hline $\begin{array}{c}\text { BM } \\
\text { analysis } \\
\text { and } \\
\text { outcome }\end{array}$ & $\begin{array}{l}\text { Investigating } \\
\text { correlation } \\
\text { between BM } \\
\text { compounds } \\
\text { (lutein, } \\
\text { choline and } \\
\text { DHA) and }\end{array}$ & $\begin{array}{c}\mathrm{N}=55 \\
\text { participants }\end{array}$ & $\begin{array}{c}\text { BM } \\
\text { samples } \\
\text { obtained } \\
\text { between } 3 \\
\text { and } 5 \\
\text { months of } \\
\text { lactation }\end{array}$ & HPLC & $\begin{array}{l}\text { A synergistic increase in } \\
\text { choline and lutein levels, } \\
\text { as well as the increase in } \\
\text { choline and DHA, } \\
\text { associated to better } \\
\text { recognition memory }\end{array}$ & $\begin{array}{l}\text { These nutrients } \\
\text { seem to act } \\
\text { synergistically in } \\
\text { the brain, } \\
\text { sustaining } \\
\text { cognitive } \\
\text { improvement }\end{array}$ & $\begin{array}{l}\text { Cheatham } \\
\text { (2015) } \\
{[84]}\end{array}$ \\
\hline
\end{tabular}




\begin{tabular}{|c|c|c|c|c|c|c|c|}
\hline & $\begin{array}{l}\text { cognitive } \\
\text { outcome }\end{array}$ & & & & & & \\
\hline $\begin{array}{c}\text { BM } \\
\text { analysis } \\
\text { and } \\
\text { outcome }\end{array}$ & $\begin{array}{l}\text { Analyzing } \\
\text { BM lipidome } \\
\text { in relation to } \\
\text { growth } \\
\text { pattern in } \\
\text { premature } \\
\text { neonates }\end{array}$ & $\begin{array}{c}\mathrm{N}=26 \text { preterm } \\
\text { neonates born } \\
\text { between } 26 \text { and } \\
36 \mathrm{w} \text { of GA and } \\
\text { fed with their } \\
\text { mother's BM. } \\
\mathrm{N}=11 \\
\text { underwent a } \\
\text { "faster" growth, } \\
\text { n=15 a "slower" } \\
\text { growth }\end{array}$ & $\begin{array}{l}\text { Samples } \\
\text { collected } \\
\text { between } 2 \\
\text { and } 7 \mathrm{w} \text { of } \\
\text { lactation }\end{array}$ & LC-MS & $\begin{array}{l}\mathrm{N}=162 \text { discriminant } \\
\text { lipids among the "faster2 } \\
\text { and "slower" group } \\
\text { samples. } \\
\text { "faster" group: higher } \\
\text { total fats (4.75 g/100 mL } \\
\text { vs 3.55 g/100 mL), } \\
\text { sphingomyelin, DGLA, } \\
\text { SFA (free and } \\
\text { triglycerides- and } \\
\text { phospholipids-bound } \\
\text { fatty acids), medium- } \\
\text { chain SFAs, n-3 long- } \\
\text { chain PUFA, such as } \\
\text { docosahexanoic, } \\
\text { eicosapentaenoic and } \\
\text { docosapentaenoic acids, } \\
\text { medium- or long-chain } \\
\text { sphingomyelins and } \\
\text { ceramides [Cer } \\
\text { (d18:1/24:0), } \\
\text { SM(d18:0/12:0)], several } \\
\text { phosphatidylcholines, } \\
\text { phosphatidylethanolamin } \\
\text { es or plasmalogen- } \\
\text { derivatives containing } \\
\text { palmitic (C16:0) or } \\
\text { palmitoleic (C16:1) acid } \\
\text { [PE (16:0/16:1), PE } \\
\text { (16:1/20:0)], stearic } \\
\text { (C18:0) or oleic (C18:1) } \\
\text { acid [PC (18:0/18:1), PC } \\
\text { (18:0/18:2) and PE (O- } \\
\text { 18:0/20:5)], DGLA, } \\
\text { C20:3 [PE (20:3/22:6), } \\
\text { PE (22:0/20:3)], or } \\
\text { DHA C22:6) [PE } \\
\text { (20:3/22:6)]. } \\
\text { Less oleic acid, oleic } \\
\text { acid-containing } \\
\text { triglyceride and DGLA- } \\
\text { oxylipin, total MUFA, } \\
\text { long-chain TG } \\
\text { containing oleic acid } \\
\text { (C18:1) [TG } \\
\text { (18:1/18:1/18:2), TG } \\
\text { (16:0/17:1/18:1) and TG } \\
\text { (18:0/18:1/18:1)], } \\
\text { eicosanoids, including } \\
\text { many DGLA-derived } \\
\text { oxylipins [15S-HpEDE, } \\
\text { 11-deoxy-16, 16- } \\
\text { dimethyland 9-deoxy-9- } \\
\text { methylene-16,16- } \\
\text { dimethyl-PGE2], LyPS } \\
\text { [LysoPS (22:0) and } \\
\text { LysoPG (22:4)] }\end{array}$ & $\begin{array}{l}\mathrm{N}=9 \text { metabolites } \\
\text { best predictors of } \\
\text { neonatal weight } \\
\text { growth, Probably } \\
\text { depending on their } \\
\text { involvement in } \\
\text { energy } \\
\text { production, } \\
\text { reduction of } \\
\text { oxidative stress, } \\
\text { modulation of } \\
\text { gastrointestinal } \\
\text { inflammation. } \\
\text { Oxylipin is } \\
\text { involved in } \\
\text { neonatal } \\
\text { metabolism and } \\
\text { outcome }\end{array}$ & $\begin{array}{c}\text { Alexandre- } \\
\text { Gouabau } \\
(2018) \\
{[82]}\end{array}$ \\
\hline $\begin{array}{c}\text { BM } \\
\text { analysis } \\
\text { and } \\
\text { outcome }\end{array}$ & $\begin{array}{l}\text { Investigating } \\
\text { BM } \\
\text { metabolomem } \\
\text { e, lipidomic, } \\
\text { glycomic, } \\
\text { FAs, and free } \\
\text { amino acids } \\
\text { content in } \\
\text { relation to the } \\
\text { growth } \\
\text { pattern of } \\
\text { premature } \\
\text { neonates }\end{array}$ & $\begin{array}{c}\mathrm{N}=26 \text { preterm } \\
\text { neonates born } \\
\text { between } 26 \text { and } \\
36 \mathrm{w} \text { of GA and } \\
\text { fed with their } \\
\text { mother's BM. } \\
\mathrm{N}=11 \\
\text { underwent a } \\
\text { "faster" growth } \\
\text { pattern while } \\
\mathrm{n}=15 \text { a "slower" } \\
\text { growth }\end{array}$ & $\begin{array}{l}\text { Samples } \\
\text { collected } \\
\text { between } 2 \\
\text { and } 7 \mathrm{w} \text { of } \\
\text { lactation }\end{array}$ & LC-MS & $\begin{array}{l}\text { "faster" growth group: } \\
\text { higher essential amino } \\
\text { acid, branched-chain, } \\
\text { insulinotrophic and } \\
\text { gluconeogenic amino } \\
\text { acids, arginine, tyrosine, } \\
\text { LNFP, choline, } \\
\text { hydroxybutyrate, acid, } \\
\text { nicotinamide, orotic, } \\
\text { hydroxybutyric, pyruvic } \\
\text { and citraconic acids, } \\
\text { Medium chain SFAs, } \\
\text { such as pentadecanoic } \\
\text { and myristic acid, } \\
\text { (TG(46:0) and } \\
\text { TG(50:2)), } \\
\text { phospholipids (PS(38:4) } \\
\text { and PE(38:3)). total }\end{array}$ & $\begin{array}{l}\text { BM samples in } \\
\text { the "faster" } \\
\text { growth group } \\
\text { contains more } \\
\text { energy, more } \\
\text { digestible calories, } \\
\text { more aminoacids } \\
\text { promoting protein } \\
\text { synthesis and } \\
\text { immune system } \\
\text { development, } \\
\text { bioactive } \\
\text { molecules } \\
\text { preventing NEC }\end{array}$ & $\begin{array}{c}\text { Alexandre- } \\
\text { Gouabau } \\
(2019) \\
{[83]}\end{array}$ \\
\hline
\end{tabular}




\begin{tabular}{|c|c|c|c|c|c|c|c|}
\hline & & & & & $\begin{array}{c}\text { fucosylated HMOs, } \\
\text { LNFPI, di-fucosylated } \\
\text { HMOs, LNDFH, pLNH. } \\
\text { Lower Neutral HMO } \\
3000 \text { and di-fucosylated } \\
\text { HMO 4210b, glycine, } \\
\text { taurine, glutamate, } \\
\text { glutamine, taurine, } \\
\text { methionine, cresol and } \\
\text { benzoic acid. } \\
\text { "slower" growth: higher } \\
\text { LNFPI and 4210d, } \\
\text { 4230b and 4230c, valine } \\
\text { and glycine, Oleic acid, } \\
\text { plasmalogen-derivatives } \\
\text { (PC(P-34:2) and PE(P- } \\
36: 0) \text { ), lyso- } \\
\text { phosphatidylethanolamin } \\
\text { e-containing arachidonic } \\
\text { acid (LysoPE(20:4)), } \\
\text { ceramide } \\
\text { (Cer(18:1/22:0)) very } \\
\text { long-chain TG } \\
\text { (TG(54:4) and } \\
\text { TG(58:7)). } \\
\text { Se+ (n=21), Se- (n=5). } \\
\text { LNFP I, LNDFH and } \\
\text { pLNH highly predictive } \\
\text { only in } S e+\text { mothers, di- } \\
\text { fucosylated HMOs } \\
\text { (4230c, 4230b, 4240b, } \\
\text { and 4210d) } \\
\text { independently by } \\
\text { Sectetor status } \\
\end{array}$ & & \\
\hline $\begin{array}{l}\text { Micro- } \\
\text { nutrients }\end{array}$ & $\begin{array}{l}\text { Detecting BM } \\
\text { levels of } \\
\text { thiamin, } \\
\text { riboflavin, } \\
\text { FAD, } \\
\text { nicotinamide } \\
\text { and pyridoxal } \\
\end{array}$ & $\begin{array}{l}\text { Mothers from } \\
\text { Cameroon, } \\
\text { China, India, } \\
\text { Malawi, USA }\end{array}$ & $\begin{array}{l}\mathrm{N}=80 \mathrm{BM} \\
\text { samples } \\
\text { collected } \\
\text { during the } \\
1^{\text {st }} \text { month }\end{array}$ & UPLS-MS & $\begin{array}{l}\text { Thiamin, niacin and B-6 } \\
\text { levels higher in MM. } \\
\text { USA: higher } \\
\text { nicotinamide. Malawi } \\
\text { and USA: lower } \\
\text { Pyridoxal. Cameroon: } \\
\text { high thiamin } \\
\end{array}$ & $\begin{array}{l}\text { BM influenced by } \\
\text { geographic origin } \\
\text { and maternal diet. } \\
\text { Lactation stage } \\
\text { should be } \\
\text { standardized }\end{array}$ & $\begin{array}{c}\text { Hampel } \\
(2012) \\
{[87]}\end{array}$ \\
\hline$\underset{\text { contaminants }}{\mathrm{BM}}$ & $\begin{array}{l}\text { The first } \\
\text { longitudinal } \\
\text { study to } \\
\text { describe BM } \\
\text { pesticides' } \\
\text { concentration, } \\
\text { its changes } \\
\text { during the } \\
1^{\text {st }} \text { year of } \\
\text { lactation and } \\
\text { associations }\end{array}$ & $\begin{array}{l}\mathrm{N}=16 \text { West } \\
\text { Australian } \\
\text { mothers }\end{array}$ & $\begin{array}{l}\mathrm{N}=99 \\
\text { samples } \\
\text { collected } \\
\text { at } 2,5,9 \\
\text { and } 12 \\
\text { months of } \\
\text { lactation }\end{array}$ & GC-MS & $\begin{array}{c}\text { P,p'-DDE the most } \\
\text { abundant, detected in } 83 \\
\text { samples }(83 \%) . \text { Mean } \\
\text { concentration } 52.25 \pm \\
49.88 \mathrm{ng} / \mathrm{g} \text { fat. } \\
\text { P,p'-DDT } 27.67 \pm 20.96 \\
\text { ng/g fat. } \\
\beta \text {-HCH } 48.00 \pm 22.46 \\
\text { ng/g fat }\end{array}$ & $\begin{array}{c}-P, p \text { '-DDE } \\
\text { decreased along } \\
\text { the } 1^{\text {st }} \text { year of } \\
\text { lactation; not } \\
\text { significantly } \\
\text { correlated with } \\
\text { infant growth. } \\
\text { Neonatal daily } \\
\text { DDTs intake 14- } \\
1000 \text { times lower } \\
\text { than reference } \\
\text { values and } \\
\text { decreased along } \\
1^{\text {st }} \text { year }\end{array}$ & $\begin{array}{c}\mathrm{Du}(2016) \\
{[90]}\end{array}$ \\
\hline$\underset{\text { contaminants }}{\mathrm{BM}}$ & $\begin{array}{l}\text { wrowth and } \\
\text { neonatal daily } \\
\text { intake of } \\
\text { pesticides }\end{array}$ & $\begin{array}{l}\mathrm{N}=40 \text { West } \\
\text { Australian } \\
\text { mothers }\end{array}$ & $\begin{array}{c}\mathrm{N}=40 \\
\text { samples } \\
\text { collected } \\
\text { at } 2,5,9 \\
\text { and } 12 \\
\text { months of } \\
\text { lactation }\end{array}$ & GC-MS & $\begin{array}{l}\text { P,p'-DDE (traces): mean } \\
\text { concentration } 62.8 \pm \\
54.5 \mathrm{ng} / \mathrm{g}\end{array}$ & $\begin{array}{l}\text { P,p'-DDE not } \\
\text { associated with } \\
\text { infant growth } \\
\text { outcomes. } \\
\text { Neonatal daily } \\
\text { intake at least } 59 \\
\text { fold below } \\
\text { recommendations } \\
\end{array}$ & $\begin{array}{c}\mathrm{Du}(2017) \\
{[91]}\end{array}$ \\
\hline$\underset{\text { contaminants }}{\mathrm{BM}}$ & $\begin{array}{l}\text { Validating a } \\
\text { new method } \\
\text { to detect } \\
\text { SSRI in BM. } \\
\text { Ongoing } \\
\text { study }\end{array}$ & $\begin{array}{c}\text { Sample } \\
\text { characteristics } \\
\text { not published } \\
\text { yet }\end{array}$ & $\begin{array}{c}\mathrm{N}=2 \\
\text { samples } \\
\text { from each } \\
\text { SSRI- } \\
\text { treated } \\
\text { mother } \\
\text { during the } \\
1^{\text {st }} \text { and } / \text { or } \\
4^{\text {th }} \mathrm{W} \\
\text { postpartum }\end{array}$ & $\begin{array}{l}\text { HPLC-ESI- } \\
\text { MS } \\
\text { coupled to } \\
\text { LC-MS }\end{array}$ & $\begin{array}{l}\text { Results not fully } \\
\text { published yet }\end{array}$ & $\begin{array}{c}\text { RID ranges } \\
\text { between } 0.5 \% \text { and } \\
9 \%\end{array}$ & $\begin{array}{l}\text { Weisskopf } \\
\text { (2017) } \\
\text { [92] }\end{array}$ \\
\hline$\underset{\text { contaminants }}{\mathrm{BM}}$ & $\begin{array}{l}\text { Investigating } \\
28 \text { mycotoxin } \\
\text { in BM }\end{array}$ & $\begin{array}{c}\mathrm{n}=22 \text { Nigerian } \\
\text { mothers }\end{array}$ & $\begin{array}{c}\mathrm{n}=75 \mathrm{BM} \\
\text { samples }\end{array}$ & LC-MS & $\begin{array}{c}\text { Many samples not } \\
\text { contaminated or } \\
\text { minimally contaminated } \\
\text { with beauvericin }(56 \%) \text {, }\end{array}$ & $\begin{array}{l}\text { Tolerable daily } \\
\text { mycotoxin intakes } \\
\text { were not exceeded }\end{array}$ & $\begin{array}{c}\text { Braun } \\
(2018) \\
{[93]}\end{array}$ \\
\hline
\end{tabular}




\begin{tabular}{|c|c|c|c|c|c|c|c|}
\hline & & & & & $\begin{array}{c}\text { enniatins B (9\%), } \\
\text { ochratoxin A (15\%) and } \\
\text { aflatoxin M1 (1\%). } \\
\text { Beauvericin the most } \\
\text { abundant (up to } 0.019 \\
\text { ng/mL) } \\
\end{array}$ & & \\
\hline$\underset{\text { contaminants }}{\mathrm{BM}}$ & $\begin{array}{c}\text { Evaluating } \\
\text { BM } \\
\text { adulterants. } \\
\text { Different } \\
\text { kinds of milk } \\
\text { were } \\
\text { compared to } \\
\text { BM }\end{array}$ & N.r. & $\begin{array}{l}\mathrm{N}=10 \mathrm{BM} \\
\text { samples } \\
\text { collected at } \\
\text { various } \\
\text { lactation } \\
\text { times }\end{array}$ & $\begin{array}{c}\text { High } \\
\text { performanc } \\
\text { e CIL } \\
\text { LC-MS }\end{array}$ & $\begin{array}{l}\mathrm{N}=1043 \text { metabolites } \\
\text { detected in } \mathrm{BM}, \mathrm{n}=2925 \\
\text { in goat milk (among } \\
\text { these, } \mathrm{n}=834 \text { in common } \\
\text { with } \mathrm{BM}), \mathrm{n}=2670 \text { in } \\
\text { cow milk ( } \mathrm{n}=851 \text { in } \\
\text { common with BM), } \\
\mathrm{n}=1348 \text { in almond milk } \\
(\mathrm{n}=488 \text { in common with } \\
\mathrm{BM}), \mathrm{n}=2562 \text { in soy } \\
\text { milk }(\mathrm{n}=583 \text { in common } \\
\text { with BM), } \mathrm{n}=1553 \text { in } \\
\text { FM ( } \mathrm{n}=518 \text { in common } \\
\text { with BM) }\end{array}$ & $\begin{array}{c}\text { Metabolomics can } \\
\text { detect differences } \\
\text { between non- } \\
\text { adulterated BM } \\
\text { and BM } \\
\text { containing } 5 \% \text { or } \\
\text { more adulterants }\end{array}$ & $\begin{array}{c}\text { Mung } \\
\text { (2018) } \\
{[94]}\end{array}$ \\
\hline$\underset{\text { contaminants }}{\mathrm{BM}}$ & $\begin{array}{l}\text { Detection of } \\
\text { BM } \\
\text { environmenta } \\
1 \text { toxicants in } \\
\text { relation to } \\
\text { neonatal gut } \\
\text { microbiome } \\
\text { at } 1 \text { month }\end{array}$ & $\begin{array}{c}\mathrm{N}=267 \\
\text { Norwegian } \\
\text { mothers }\end{array}$ & $\begin{array}{c}\text { BM } \\
\text { collected } \\
\text { each } \\
\text { morning for } \\
8 \\
\text { consecutive } \\
\text { days, } \\
\text { (2 w and } 2 \\
\text { months of } \\
\text { lactation) } \\
\end{array}$ & $\begin{array}{l}\text { GC-MS } \\
\text { LC-MS }\end{array}$ & $\begin{array}{l}\text { Polybrominated flame } \\
\text { retardants (especially } \\
\text { PBDE-28), PFOA, } \\
\text { PFOS and dioxin-like } \\
\text { polychlorinated } \\
\text { biphenyls (especially } \\
\text { PCB-167) were detected }\end{array}$ & $\begin{array}{c}\text { Such } \\
\text { contaminants are } \\
\text { associated with } \\
\text { less microbiome } \\
\text { diversity in infant } \\
\text { gut }\end{array}$ & $\begin{array}{c}\text { Iszatt } \\
(2019) \\
{[95]}\end{array}$ \\
\hline
\end{tabular}

Table 1. Summary of metabolomic studies on human breast milk (BM). Update of the review of Cesare-Marincola et al [34].

${ }^{1} \mathrm{H}-\mathrm{NMR}=$ nuclear magnetic resonance spectroscopy; 2' $\mathrm{FL}=2$ 'fucosyllactose; 3' $\mathrm{FL}=3$ 'fucosyllactose; 3' $\mathrm{SL}=3^{\prime}$ ' sialyllactose; 6' $\mathrm{SL}=6$ ' sialyllactose; $\beta$ - $\mathrm{HCH}=$ beta-Hexachlorocyclohexane; $\mathrm{AGA}=$ appropriate for $\mathrm{GA} ; \mathrm{AMP}=$ adenosine monophosphate; $\mathrm{AKI}=$ acute kidney injury; $\mathrm{BM}=\mathrm{breast}$ milk; $\mathrm{BW}=$ birth weight; $\mathrm{CE}-\mathrm{MS}=$ capillary electrophoresis-mass spectrometry; $\mathrm{CIL}=$ chemical isotope labeling; $\mathrm{COX}=$ cyclooxygenase; $\mathrm{d}=\mathrm{days}$; DGLA=dihomo-linolenic acid; DHA=docosahexaenoic acid; DHEA=Docosahexaenoylglycerol; dUMP=deoxyuridine monophosphate; FAs= fatty acids; FAAs=free amino acids; $\mathrm{FM}=$ formula milk; $\mathrm{FAD}=$ flavin-adenine dinucleotide; $\mathrm{GA}=$ gestational age; $\mathrm{GC}-\mathrm{MS}=$ gas chromatography mass spectrometry; GC-TOFMS=Gas chromatography-time-of-flight mass spectrometry; GDM=gestational diabetes mellitus; HD=hemodyalisis; HMOs=human milk holigosaccharides; HPLC=high-performance liquid chromatography; HPLC-MS= high-performance liquid chromatographymass spectrometry; HPLC-QTOFMS=high-performance liquid chromatography-quadrupole-time of flight mass spectrometry; HPLC-ESI-MS=HPLC coupled to electrospray mass spectrometry; iTRAQ=isobaric tags for relative and absolute quantification technology; LC-MM=mature milk; MS=liquid chromatography tandem mass spectrometry; LDL= low density lipoproteins; LGA=large for GA; LNDFH=Lacto-N-difucosyl-hexaose; LNFP=lacto-N-fucopentaose; LnNT= Lacto-N-neotetraose; LOX=lipoxygenase; LPC=Lyso-phosphatidylcholine; LTB4=Leukotriene B4; LyPS=Lyso-phospholipids; MUFAs=monounsaturated fatty acids; NEFAs=non-esterified fatty acids; P,p'-DDE=p,p'dichlorodiphenyldichloroethylene; P,p'-DDT=p,p'-díchlorodiphenyltrichloroethane; $\quad \mathrm{pLNH}=$ lacto-N-hexaose; $\quad \mathrm{PFOA}=$ Perfluorooctanoic $\quad$ acid; PFOS=surfactant perfluorooctanesulfonic acid;

PUFAs=polyunsaturated fatty acids; RID=relative infant circulating dose; SCFAs= short chain fatty acids; $S e+=$ secretors; $S e-=$ non secretors; SFAs=saturated fatty acids; $\mathrm{SGA}=$ small for $\mathrm{GA}$; $\mathrm{SSRI}=$ selective serotonin reuptake inhibitors; SPM=pro-resolving mediators involved in host defense; TCA=tricarboxylic acid; TG=triglycerides; TM= transition milk; UFAs=unsaturated fatty acids; UPLC-MS=ultra-performance liquid mass spectrometry; UPLC-QTOFMS=ultra-performance liquid chromatography-quadrupole-time-of- flight mass spectrometry; VLDL= very low density lipoproteins; $w=w e e k s$ 